\title{
Liderança como Fator de Sucesso na Gestão Escolar: Estudo de Caso numa Escola Privada na Região Norte de Portugal
}

\section{Leadership as Factor of Success in School Management: Case Study in a Private School in the Northern Region of Portugal}

\author{
VANESSA ROCHA LIMA E SOUZA* \\ THIAGO SILVA E SOUZA** \\ RANNIÉRY MAZZILLY SILVA DE SOUZA*** \\ ALEXANDRE DE FREITAS CARNEIRO****
}

\section{RESUMO}

A partir da literatura, observa-se que teorias de liderança têm por propósito examinar o comportamento dos líderes que são capazes de conquistar a confiança e o apoio de seus seguidores organizacionais, levando-os a um aumento de produtividade e satisfação. Estudos distinguem a abordagem transformacional da liderança como responsável por altos níveis de motivação e compromisso dos seguidores. Analisar o contributo da liderança para o sucesso na gestão escolar foi o objetivo principal desta investigação. Para isso, optou-se pela tipologia mista, na forma de um estudo de caso único, com uma abordagem quantiquali, de cunho descritivo-interpretativo. Os instrumentos de coleta de dados utilizados foram o Multifactor Leadership Questionnaire (MLQ-5x), aplicado aos docentes e coordenadores pedagógicos, assim como um inquérito por entrevista à diretora da escola. Constatou-se que o estilo de liderança transformacional, de cunho

* Mestrado em Ciências da Educação, Universidade Católica Portuguesa. vanessarlima@ hotmail.com

** Mestrado em Estudos de Gestão. Universidade do Minho. imthiagosouza@hotmail.com

*** Doutorando em Administração. Universidade do Estado do Amazonas. Universidade do Minho. ranniery34@globo.com

**** Doutorando em Administração. Universidade Federal de Rondônia. Universidad Nacional de Misiones 
democrático e inserido num modelo organizacional que se distingue por uma imagem de clã, resulta na eficácia, na satisfação e, em especial, no reforço ao empenhamento motivacional dos agentes educadores. Por conseguinte, depreende-se que uma liderança motivada, inovadora, experiente e consciente de sua função estratégica para o alcance dos objetivos organizacionais contribui para o sucesso da gestão escolar.

Pavavras-chave: Liderança Escolar; Gestão Escolar; Multifactor Leadership Questionnaire.

\section{Abstract}

From the literature, it can be observed that leadership theories are intended to examine the behavior of leaders who are able to earn the trust and the support of their organizational subordinated, leading them to an increase in their productivity and satisfaction. Studies point out the transformational leadership approach as responsible for high levels of motivation and commitment on behalf of the subordinated. Analyzing the contribution of leadership to the success in school management was the main objective of this research. For that, a mixed methodology was used, in the form of a single case study, with a quantitative and qualitative approach, being descriptive and interpretative. The data collection instruments used were the Multifactor Leadership Questionnaire (MLQ-5x), applied to teachers and to coordinators, as well as an interview survey directed to the school principal. It was found that the transformational leadership style, democratic in its nature and inserted in an organizational model that is defined by an image of clan, results in efficiency, satisfaction and, especially, in the strengthening of the motivational commitment of the educators. Therefore, it is inferred that a motivated, innovative and experienced leadership, aware of its strategic role for the achievement of the organizational goals, contributes to the success of the school management.

Keywords: School Leadership; School management; Multifactor Leadership Questionnaire.

\section{INTRODUÇÃO}

No início dos anos 80, permeada de certo pessimismo sobre teorias e pesquisas sobre liderança, observa-se uma tendência de se 
analisar o líder não mais como uma pessoa de atitudes mecânicas, prescritivas e hierarquicamente padronizadas. Sob o contexto educacional, em que pese "reservas que autores assumem em relação a importar para as escolas modelos organizativos e de liderança do mundo empresarial" (TRIGO; COSTA, 2008, p.563), há que se ressaltar, sobretudo na perspectiva de como ambos lidam com pessoas, comunidade e buscam o sucesso de suas organizações e colaboradores, a relevância na melhoria dos níveis de eficácia.

Estudos relatam ser "interessante problematizar a natureza da relação entre os estilos de liderança e gestão, e os resultados escolares e o seu impacto no desenvolvimento democrático da escola" (TORRES; PALHARES, 2009, p.77). Da mesma forma, buscam demonstrar como se processa a construção de sua cultura organizacional, constatando que "a escola, como organização, não ficou imune, tampouco indiferente, ao contexto político-ideológico e econômico internacional, que contribuiu para a redefinição da agenda científico-investigativa" (TORRES, 2003, p.151-152).

Destarte, por ser um tema vasto em conceitos, estudos e modelos, perspectivar uma organização como locus de sua cultura e liderança tende a aproximar a investigação de uma concessão mais interpretativa e subjetiva, onde essas variáveis, apesar de centralmente reguladas, são construídas a partir da ação dos atores envolvidos no ambiente escolar (FERREIRA; TORRES, 2012).

Segundo a Associação Empresarial de Portugal (AEP, 2011, p.6), a expressão "boas práticas" (best practices), oriunda da gestão empresarial, tem por objetivo "identificar os modos mais eficientes e mais eficazes de levar a cabo uma atividade ou tarefa, segundo determinados procedimentos estabelecidos". Avocada ao contexto escolar, observa-se a "boa" gestão como um "processo de mobilização e orientação de talentos e esforço coletivo na escola, em associação com a organização de recursos e processos onde esta instituição desempenha de forma efetiva seu papel social e objetivos educacionais" (LÜCK, 2008, p. 96).

Freitas (2011) esclarece que o diploma que regula o modelo de gestão das escolas em Portugal, na sequência do Decreto-Lei $\mathrm{n}^{\mathbf{0}}$. 75, de 22 de abril de 2008, salvaguarda um modelo de gestão unipessoal, cujos objetivos são: (i) reforçar a participação das famílias 
e comunidades na direção das escolas; (ii) fortalecer a autonomia das escolas e (iii) estimular a liderança das escolas. Por conseguinte, tutela a figura do diretor como o "líder" forte, como sendo o "rosto da escola", também responsável por sua comunidade escolar, colocando em prática as diretrizes emanadas do poder central.

Para Fullan (2003), liderar escolas requer coragem e capacidade para criar novas culturas, sendo possível projetar ao diretor não só a responsabilidade da administração dos recursos financeiros, mas a coordenação e liderança de todos os seus recursos (materiais e humanos) de maneira eficaz, resultando, assim, no sucesso de seus alunos, realização de seus funcionários e a motivação diária de toda comunidade escolar, em busca do conhecimento e do crescimento, sejam eles profissionais e pessoais.

Por fim, Lück (2008) pondera que as coisas boas ou positivas são a capacidade de realçar e melhorar a performance do aluno, aumentar a competência dos professores, privilegiar o maior envolvimento dos pais e membros da comunidade, o compromisso dos alunos, a satisfação geral e o entusiasmo em progredir, enfim, acima de tudo fomentar um enorme orgulho no sistema com um todo, no que conceitua como liderança compartilhada.

Neste contexto, o âmbito de pesquisa foi de uma instituição de ensino privada, localizada na região do Minho, norte de Portugal, que possui na cultura organizacional transnacional (formada por colaboradores de diversas nacionalidades) seu principal desafio, assim como referência de liderança escolar, amparados pelos resultados positivos apresentados por seus estudantes no transcorrer de sua jornada educacional, principalmente, no produto final entregue à sociedade, além de prêmios institucionais diversos.

Diante das circunstâncias ora apresentadas, resta esclarecer que a investigação teve como principal objetivo analisar o contributo da liderança para o sucesso da gestão escolar, conjugando uma base categorial (análise qualitativa) a uma base estatística (análise quantitativa), suportada pelo modelo Multifactor Leadership Questionnaire (MLQ).

O artigo está estruturado em outras três seções, para além desta introdução. Na seção 2, o referencial teórico abrange sobre liderança, a "boa" gestão escolar e a cultura organizacional em contexto 
escolar; na seção 3, os procedimentos metodológicos; a análise e discussão dos resultados constam da seção 4; e, por fim, na seção 5 , as conclusões.

\section{ENQUADRAMENTO TEÓRICO}

\subsection{A Liderança em Discussão}

Conceito alvo de inúmeros estudos no contexto das ciências sociais e humanas, "a influência interpessoal exercida numa situação, sendo conduzida por meio do processo de comunicação humana, levando à consecução de um ou mais objetivos específicos" (CHIAVENATO, 2007, p. 307) é uma dentre as mais de 220 definições propostas entre as décadas de 20 e 90 do século passado para Liderança (NYE, 2009).

Da literatura, se depreende que o líder tende a ser uma pessoa capaz de se ajustar ao nível de maturidade dos seus comandados, desenvolvendo competências pertinentes à função, especializando-se com certa frequência. No conceito de Tucker e Russel (2004), um líder competente busca entender a teoria, aplicá-la e refletir sobre os seus resultados, sendo capaz de construir uma estrutura dinâmica que lhe permita avaliar suas ações futuras em um processo contínuo de melhoria.

Kouzes e Posner (2009, apud FREITAS, 2011) defendem que as competências da liderança podem ser adquiridas por todos, desde que sejam capazes de liderarem a si próprios e acreditarem que conseguem. Destacam a necessidade de os líderes estarem apaixonados pela liderança, pelas pessoas que fazem parte da organização e por aquilo que ela produz, porque a liderança não é um assunto racional, mas sim um assunto emocional.

Sendo assim, observa-se uma grande a diversidade de estudos com o escopo de clarificar e, sobretudo, classificar propostas de teorias sobre estilos de liderança, refletindo sobre as consequências que derivam de suas utilizações. Em que pese a existência de copiosos ensaios acadêmico-científicos os relacionando a conceitos como eficácia organizacional e capacidade de atingir objetivos mensuráveis de sucesso, propõe-se a harmonização taxonômica conforme (i) a teoria dos traços, (ii) a teoria comportamental, (iii) a teoria contin- 
gencial e (iv) a teoria da nova liderança (BRYMAN, 1992; CUNHA et al, 2007; FIOL, HARRIS; HOUSE, 1999; YUKL, 2010).

Sustentada na chamada "Teoria dos Grandes Homens", de onde se destacam líderes como Mahatma Ghandi (1869-1948), Winston Churchill (1874-1965), Adolf Hitler (1889-1945) e Martin Luther King (1929-1968), os quais se sobrepuseram à grande massa por serem considerados de classes superiores, a Teoria dos Traços tem como propósito desvendar os traços físicos, características de personalidade e capacidade apontadas como atributos de um líder.

Portanto, teses são fundamentadas a partir da proposta de que se nasce líder, em oposição à perspectiva de se edificar um líder, evidenciadas a partir de uma relação direta entre líderes eficazes e certos traços-chave de perfil de liderança como (i) drive (energia, ambição, iniciativa, tenacidade); (ii) honestidade e criatividade; (iii) conhecimento do negócio; (iv) autoconfiança; (v) motivação para liderar e (vi) habilidade cognitiva (BARRACHO, 2012; KIRKPATRICK; LOCKE, 1991; TEJEDA; SCANDURA; PILLAI, 2001).

Resultados insatisfatórios da teoria dos traços, em estudos de campo sobre liderança organizacional, creditaram a Kurt Lewin, em 1938, o pioneirismo na análise do paradigma comportamental do líder, isto é, sob a denominação de Teoria Comportamental, defendeu-se que existe um perfil universal de comportamento mais eficaz, padrão e compatível a cada situação enfrentada por um líder (JESUÍNO, 1987).

Acessório, White e Lippitt (1975) pormenorizaram o estudo do estilo de liderança comportamental ao categorizá-lo em (i) liderança autocrática, onde o líder é dominador e centralizador nas decisões; (ii) liderança democrática, onde o líder procura debater as diretrizes e decisões, sendo objetivo nos fatos, estimulando e assistindo seu grupo; e a (iii) liderança laissez-faire, onde o líder se posiciona como mais um membro do grupo, sem qualquer tentativa de avaliar ou regular o curso dos acontecimentos, com liberdade completa para as decisões grupais.

Já a Teoria Contingencial, ou situacional, tem seus estudos classificados conforme a (i) primeira geração, a qual propõe uma relação direta dos estilos de liderança adotados com diferentes tipos de situação, isto é, defende-se que é possível determinar quais 
as contingências que tornam mais eficaz um ou outro estilo; e a (ii) segunda geração, cujo foco está no efetivo comportamento e não nos traços de personalidade dos líderes, frente a cada situação vivenciada.

No contexto dos estudos da $2^{a}$ geração, destaque para o modelo de Hersey e Blanchard ${ }^{1}$, ao integrar à análise situacional a variável (i) comportamento do líder, exteriorizada a partir do cruzamento de suas orientações para as tarefas e para o relacionamento interpessoal da equipe; e a variável (ii) maturidade dos colaboradores, não só na função desempenhada (conhecimento, experiência, competências na execução das tarefas), mas psicológica, manifestada pela autoconfiança, empenhamento e motivação na execução de suas funções (CUNHA et al., 2007; JESUÍNO, 1987).

Por fim, designada como Teoria da Nova Liderança, paradigma neocarismático dos estudos sobre liderança, têm-se nos ensaios a identificação de um líder que centra sua atenção na criação e gestão da cultura de sua organização, isto é, um líder cultural que começa a ser percebido, entre os seus seguidores, como aquele que define o seu modo de agir segundo a realidade organizacional e os valores ali existentes (BRYMAN, 1992; COSTA, MENDES; VENTURA, 2000; FIOL; HARRIS; HOUSE, 1999). Por conseguinte, observa-se o crescimento de estudos sob a ótica da relação entre a liderança e eficiência na gestão, enfatizando o apelo emocional e o relevante compromisso por parte dos liderados, com destaque para ensaios que enfatizam compreender teorizações como as de (i) liderança carismática, (ii) transacional e (iii) transformacional.

Na liderança carismática, identificam-se líderes sensíveis às limitações organizacionais, que bem articulam uma visão atrativa para a realização da missão, acrescentando um componente ideológico, que oferece como recompensa a própria realização da tarefa. Logo, assenta-se na percepção de seus seguidores, a figura da pessoa dotada de capacidades e talentos excepcionais, que alicerçada no carisma, tem no apelo emocional, estímulo para a identificação do coletivo, resultando no estabelecimento de padrões, valores e criação de metas (YUKL, 1999).

Hersey, Paul \& Blanchard, Kenneth (1988), Management of organizational behavior: Utilizing human resources (5 $5^{\mathrm{a}}$ ed.), Englewwod Clifs, USA: Prentice-Hall. 
Já na liderança transacional, constatam-se líderes que motivam seus seguidores no sentido das metas estabelecidas mediante o pleno esclarecimento dos papéis e requisitos de cada tarefa a ser desempenhada (ROBBINS, 2002). Nos estudos de Leithwood e Duke (1999), identifica-se na liderança transacional a existência de "trocas" entre o líder e os seus seguidores, quando estas forem necessárias, levando-se em consideração a recompensa por comportamentos apropriados e a punição daqueles improdutivos que, segundo Cunha et al. (2007), podem ser assim estruturados:

(i) recompensa contingente: onde o líder clarifica ao seguidor aquilo que deve fazer para ser recompensado pelo esforço,

(ii) gestão por exceção ativa: onde o líder monitora o desempenho dos seguidores e adota ações corretivas se os mesmos não alcançam os padrões estabelecidos,

(iii) gestão por exceção passiva: onde o líder aguarda que os problemas ocorram para que, então, sejam tomadas ações corretivas, e

(iv)liderança laissez-faire: onde o líder abstém-se de tentar influenciar os subordinados.

Por fim, na liderança transformacional percebem-se líderes inspiradores, que buscam ampliar e elevar os interesses de seus seguidores ao gerar a conscientização e aceitação dos propósitos e da missão do grupo, incentivando-os a conjeturar além de seus interesses, assistindo o bem dos demais (SCHERMERHORN; HUNT; OSBORN, 1999).

Segundo Cunha et al. (2007, p. 371), a liderança transformacional "refere-se ao processo através do qual os líderes fomentam o empenhamento dos seguidores e os induzem a ultrapassar seus auto interesses em prol dos objetivos da organização". Em complemento, para Bergamini $(2009$, p.59) o líder procura risco quando há uma oportunidade, em que há valiosa recompensa e "é reconhecido como sendo mais bem-sucedido quando o objetivo diz respeito a levar o seguidor a transcender seus próprios interesses em benefício da equipe".

Bass et al. (2003) relatam estudos que identificaram quatro componentes estruturais distintas da liderança transformacional: 
Quadro 1: Componentes da liderança transformacional.

\begin{tabular}{|c|c|}
\hline Componentes & Explanação \\
\hline $\begin{array}{l}\text { Influência idealizada } \\
\text { (carisma) }\end{array}$ & $\begin{array}{l}\text { O líder adota comportamentos (e.g. de } \\
\text { respeito e elevação moral) que ativam fortes } \\
\text { emoções nos seguidores, suscitam a confian- } \\
\text { ça e identificação destes com ele, influenciam } \\
\text { os seus ideais e os aspectos "maiores do que } \\
\text { a vida". }\end{array}$ \\
\hline $\begin{array}{l}\text { Liderança inspiracional } \\
\text { (motivação) }\end{array}$ & $\begin{array}{l}\text { O líder comunica uma visão apelativa, usa } \\
\text { símbolos para fomentar o esforço dos segui- } \\
\text { dores, atua como um modelo de comporta- } \\
\text { mento, instila otimismo. }\end{array}$ \\
\hline Estimulação intelectual & $\begin{array}{l}\text { O líder estimula nos seguidores a tomada de } \\
\text { consciência dos problemas, dos seus próprios } \\
\text { pensamentos e imaginação. Ajuda-os a reco- } \\
\text { nhecer as suas próprias crenças e valores. Fo- } \\
\text { menta-lhes o pensamento inovador/criativo, } \\
\text { Incita-os a questionarem as suas assunções. }\end{array}$ \\
\hline $\begin{array}{l}\text { Consideração indivi- } \\
\text { dualizada }\end{array}$ & $\begin{array}{l}\text { O líder atende às necessidades de desenvol- } \\
\text { vimento dos seguidores, apoiando-os, enco- } \\
\text { rajando-os, treinando-os, tenta desenvolver } \\
\text { o seu potencial, fornece-lhes feedback, delega- } \\
\text { lhes responsabilidades. }\end{array}$ \\
\hline
\end{tabular}

Fonte: Adaptado de Cunha et al. (2007, p. 373).

Oportuno enfatizar o fato de defenderem a tese de que o estágio ideal de efetividade e maturidade organizacional ocorre quando há a percepção da existência de um ambiente onde se predomina uma liderança transformacional, considerado o estilo mais apropriado ao cenário atual, onde a mudança e a imprevisibilidade estão constantemente presentes nas organizações (ANTONAKIS, 2001; AVOLIO; BASS, 2002; DEN HARTOG; VAN MUIJEN; KOOPMAN, 1997; LEITHWOOD; HARRIS; HOPKINS, 2008; PHIPPS; PRIETO, 2011; TUCKER; RUSSEL, 2004; YANG, 2014).

Para Tucker e Russel (2004), os líderes transformacionais são um imperativo em um mundo em constante mudança, com grande influência sobre a cultura da organização ao buscar alterar a estrutura existente e motivar as pessoas em alinhar seus esforços para novas visões e possibilidades. Com foco no contínuo processo de 
aprendizagem de seus seguidores, utilizam sua autoridade e poder para inspirá-los e motivá-los a confiar e seguir seus exemplos.

\subsection{A "Boa" Gestão Escolar}

Sob o contexto escolar, tem-se nos estudos de Trigo e Costa (2008 p. 579) que "uma liderança que se inspire em valores, comunique e dirija através de valores, será verdadeiramente facilitadora e inspiradora das mudanças necessárias ao aumento da qualidade e eficácia das instituições educativas".

Sendo assim, identificar traços e comportamentos diferenciais, que expliquem a maior ou menor eficácia de indivíduos com responsabilidade de chefia, por vezes sobrepõem os conceitos de liderança e gestão. Esta, segundo a doutrina dominante, se destaca por ser um processo pelo qual se mobiliza e se coordena o talento humano, coletivamente organizado, onde os componentes de equipes buscam agregar habilidades na promoção de resultados desejados (JESUÍNO, 1987; LÜCK, 2008). Cunha et al. (2007) sugerem o seguinte quadro comparativo:

\section{Quadro 2: Líderes versus Gestores.}

\begin{tabular}{|l|l|}
\hline Líderes & Gestores \\
\hline Procuram agir sobre a situação & Rendem-se à situação \\
$\begin{array}{l}\text { Questionam-se sobre o quê e o } \\
\text { porquê }\end{array}$ & $\begin{array}{l}\text { Questionam-se sobre o como e o } \\
\text { quando }\end{array}$ \\
Inovam & Administram \\
Têm perspectivas de longo-prazo & Têm perspectivas de curto-prazo \\
São originais & Imitam \\
$\begin{array}{l}\text { As competências de liderança não } \\
\text { podem ser ensinadas/aprendidas }\end{array}$ & $\begin{array}{l}\text { As competências de gestão podem } \\
\text { ser ensinadas/aprendidas }\end{array}$ \\
\hline
\end{tabular}

Fonte: Adaptado de Cunha et al. (2007, p. 334).

Os estudos de Leithwood abordam uma liderança gestionária estruturada sob 7 dimensões: (i) construção de uma visão para a escola; (ii) estabelecimento de objetivos para a escola; (iii) proporcionar estímulos intelectuais e oferecer apoio individual; (iv) modelar boas práticas e valores organizacionais; (v) demonstrar altas expectativas 
de performance; (vi) criar uma cultura escolar produtiva; e (vii) desenvolver estruturas que facilitem a participação em decisões no ambiente escolar (LEITHWOOD, 1994; LEITHWOOD; JANTZI, 1990; LEITHWOOD; JANTZI; FERNANDEZ, 1994).

Por oportuno, cabe destacar o trabalho Torres (2011, p. 101), a qual defende que "o gestor escolar tende a nortear a sua ação quotidiana, mediando permanentemente forças de sinal contrário: as pressões externas para a uniformização burocrática e as dinâmicas internas para a diversificação cultural e identitária", e a proposta de Dullewicz e Higgs (2003), a qual busca identificar e classificar competências que influenciam, diretamente, o desempenho da liderança nas organizações, agrupando-as em três tipos distintos de qualificação:

(i) qualificações intelectuais (Intellectual Qualification): perspectivas estratégicas; visão e imaginação; análise crítica e julgamento.

(ii) qualificações de gestão (Managerial Qualification): gestão de recursos; comunicação engajadora; desenvolver; capacitar; conseguir.

(iii) qualificações emocionais (Emotional Qualification): motivação; influência; conscienciosidade; sensibilidade; autoconsciência; resiliência emocional; intuitividade.

Mister esclarecer que excelência não é uma disciplina teórica, “está relacionada com as realizações tangíveis de uma organização relativamente ao que faz, na forma como o faz, nos resultados que alcança e na convicção de que estes resultados serão sustentados no futuro" (EFQM, 2002, p.9), reforçam os conceitos de liderança e constância de propósitos, onde "excelência é liderança visionária e inspiradora, indissociada de uma constância de propósitos (...) organizações excelentes têm líderes que definem e comunicam um rumo claro para as suas organizações" (EFQM, 2002, p.5).

Com amparo nos estudos de Leithwood et al. (2004), é possível concluir que existem uma série de fatores relevantes e interdependentes responsáveis pela aprendizagem e pela boa qualidade do ensino, nomeadamente políticas educativas, a infraestrutura da escola, a experiência dos líderes (formais e informais), as práticas docentes e outras partes interessadas na comunidade escolar. Por conseguinte, as lideranças de escolas eficazes contribuem para a aprendizagem de seus alunos, mas são fundamentais para a reorganização e/ou transformação de toda a estrutura do ambiente escolar. 


\subsection{A Cultura Organizacional em Contexto Escolar}

Na concepção de Deshpandé, Farley e Webster Jr. (1993), cultura organizacional é definida como um modelo de valores e crenças compartilhadas que auxiliam os indivíduos a compreenderem o funcionamento das organizações e assim lhes fornece normas e padrões de comportamento a serem adotados em seu dia a dia.

Torres (2003), ao conceituar cultura em contexto escolar, elucida que o ambiente escolar é um campo socialmente construído, isto é, grande destaque se deve para a tensão existente entre seus aspectos formais e informais, seus aspectos explícitos e implícitos do quotidiano, assim como suas questões objetivas e subjetivas que desafiam a gestão, tanto de dentro quanto de fora da organização. Por conseguinte, observa-se que aspectos estruturais e de simples ação administrativa se desenvolvem em um continuum de consolidação da cultura organizacional.

Quadro 3: Conceito de cultura em contexto escolar.

\begin{tabular}{|c|c|c|c|c|}
\hline $\begin{array}{l}\text { Planos } \\
\text { analíticos }\end{array}$ & $\begin{array}{l}\text { Regras } \\
\text { organiza- } \\
\text { cionais }\end{array}$ & $\begin{array}{l}\text { Enfase domi- } \\
\text { nante }\end{array}$ & $\begin{array}{l}\text { Focalização da cul- } \\
\text { tura organizacional }\end{array}$ & $\begin{array}{l}\text { Manifestações } \\
\text { da cultura or- } \\
\text { ganizacional }\end{array}$ \\
\hline \multirow{3}{*}{$\begin{array}{l}\text { Plano de } \\
\text { orienta- } \\
\text { ções para } \\
\text { a ação }\end{array}$} & Formais & $\begin{array}{l}\text { Estrutura/cul- } \\
\text { tura societal } \\
\text { (exterior) }\end{array}$ & $\begin{array}{l}\text { Cultura como variá- } \\
\text { vel independente e } \\
\text { externa }\end{array}$ & $\begin{array}{l}\text { Perspectiva } \\
\text { integradora }\end{array}$ \\
\hline & $\begin{array}{l}\text { Não for- } \\
\text { mais }\end{array}$ & $\begin{array}{l}\text { Grupos/cultura } \\
\text { organizacional } \\
\text { (interior) }\end{array}$ & $\begin{array}{l}\text { Cultura como va- } \\
\text { riável dependente e } \\
\text { interna }\end{array}$ & $\begin{array}{l}\text { Perspectiva } \\
\text { integradora } \\
\text { e diferencia- } \\
\text { dora }\end{array}$ \\
\hline & Informais & $\begin{array}{l}\text { Processo da } \\
\text { construção da } \\
\text { cultura } \\
\text { Acção dos } \\
\text { actores }\end{array}$ & $\begin{array}{l}\text { Cultura como me- } \\
\text { táfora }\end{array}$ & $\begin{array}{l}\text { Multiperspec- } \\
\text { tivação }\end{array}$ \\
\hline $\begin{array}{l}\text { Plano } \\
\text { da ação } \\
\text { organiza- } \\
\text { cional }\end{array}$ & $\begin{array}{l}\text { Efetiva- } \\
\text { mente } \\
\text { actualiza- } \\
\text { das }\end{array}$ & $\begin{array}{l}\text { Processo da } \\
\text { construção da } \\
\text { cultura } \\
\text { Acção prati- } \\
\text { cada }\end{array}$ & $\begin{array}{l}\text { Cultura como me- } \\
\text { táfora }\end{array}$ & $\begin{array}{l}\text { Multiperspec- } \\
\text { tivação }\end{array}$ \\
\hline
\end{tabular}

Fonte: Adaptado de Torres (2003). 
Com amparo na síntese de informações do quadro 10 e dentro dos objetivos desta investigação, oportuno clarificar as denominadas modalidades de partilha das manifestações da cultura organizacional propostas por Torres (2003, p.188-191):

a) Perspectiva integradora: enfatiza os aspectos mais consensuais da cultura, sendo esta tanto mais forte e consensual quanto mais alargado for o seu grau de partilha entre os trabalhadores da organização. $\mathrm{O}$ elemento central na criação da cultura é o líder da organização, que adquire poderes de eleger os seus próprios valores e crenças como aqueles que passarão a ser impostos aos restantes membros da organização;

b) Perspectiva diferenciadora: ênfase colocada nas diferenciações culturais, nos dissensos, nos conflitos e nos antagonismos culturais emergentes numa organização. Nesta óptica, a cultura organizacional corresponderia ao denominador comum das várias subculturas existentes com a particularidade de nunca ser conceptualizada de forma homogeneizada;

c) Perspectiva fragmentadora: revela como elemento central de análise as ambiguidades inerentes às múltiplas ordens e racionalidades organizacionais, propiciando, deste modo, a emergência de uma variedade de interpretações sobre a realidade, que é, sobretudo, socialmente construída e caracterizada pela complexidade, diversidade e paradoxo.

Logo, diante da diversidade de perspectivas e modelos organizacionais educativos existentes na literatura, sublinha-se o modelo de Deshpandé, Farley e Webster Jr. (1993), o qual propõe que, a partir de quatro dimensões-chave, é possível representar a fusão das duas principais correntes teóricas do comportamento organizacional, quais sejam: (i) a perspectiva de sistemas estruturais e (ii) a perspectiva dos custos de transação. 
Figura 1: Modelos e Imagens Organizacionais.

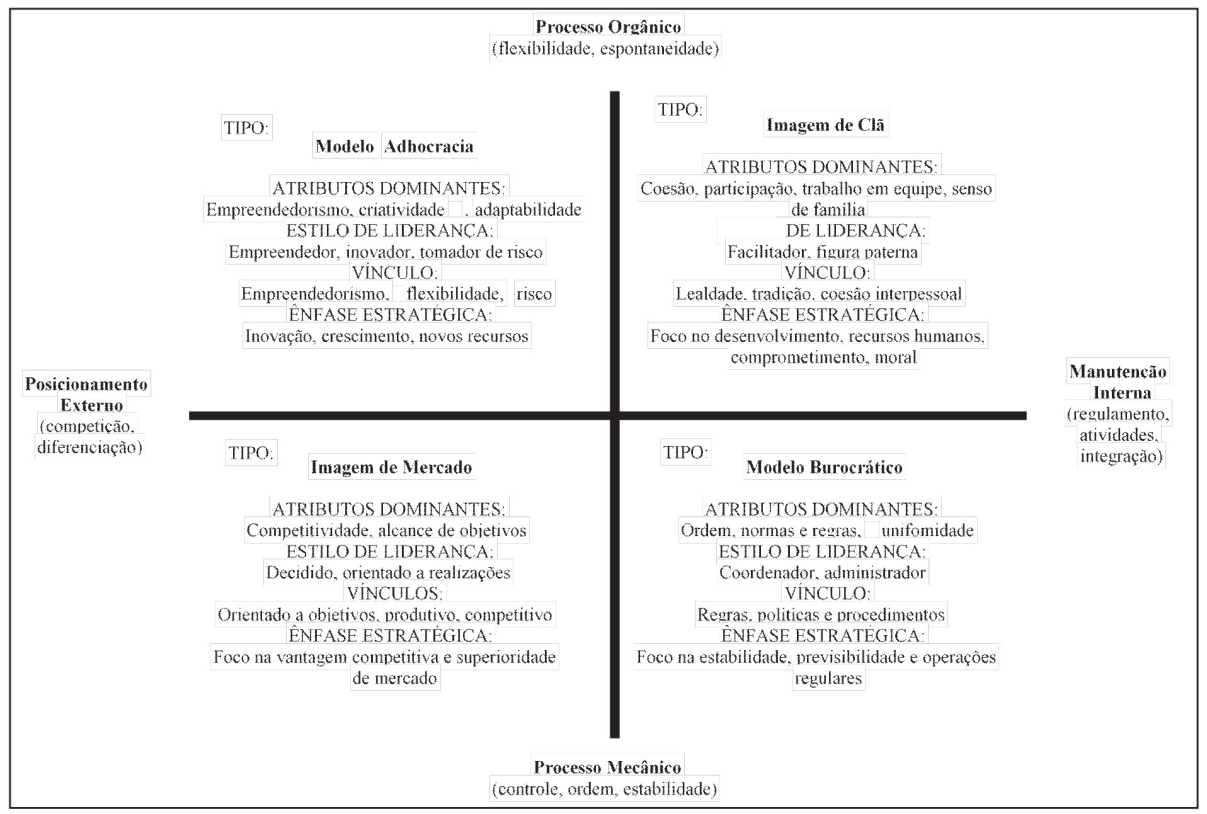

Fonte: Adaptado de Deshpandé, Farley e Webster Jr. (1993, p. 25).

Isto posto, observa-se no eixo vertical a continuidade dos processos orgânicos até os processos mecanicistas, ou seja, tem-se que a ênfase organizacional passa sobre características marcantes de flexibilidade, espontaneidade e individualidade até sua ênfase no controle, estabilidade e ordem. Já no eixo horizontal, o que se observa é a ênfase da relação organizacional com a manutenção interna de sua estratégia, isto é, seu foco na suavização das atividades e integração, passando, em momento oportuno, para um posicionamento externo, caracterizado pela concorrência e a diferenciação ambiental.

Suplementarmente, o quadro esclarece os conceitos e características envolvidas no modelo, segundo o qual se tem na "imagem de mercado" a ênfase na vantagem competitiva e superioridade de mercado, em contraponto ao "modelo burocrático", com sua ênfase na previsibilidade e no bom funcionamento dentro da organização. Em outro extremo, tem-se no modelo ad-hocrático o foco na inovação, empreendedorismo e assunção de riscos, em contraponto à imagem de clã, caracterizada pela lealdade, a tradição e a ênfase na manutenção interna. 


\section{Quadro 4: Modelos e Imagens Organizacionais.}

\begin{tabular}{|c|c|}
\hline $\begin{array}{l}\text { Modelos/Ima- } \\
\text { gens }\end{array}$ & Características \\
\hline Burocrático $^{a}$ & $\begin{array}{l}\text { Evidencia a estrutura hierárquica da autoridade legal } \\
\text { inerente ao posto hierárquico, a orientação da organiza- } \\
\text { ção para o alcance de objetivos e finalidades, a divisão } \\
\text { e especialização do trabalho, a existência de regras e } \\
\text { regulamentos, as relações impessoais para certificar a } \\
\text { neutralidade e a progressão por mérito. A burocracia } \\
\text { reflete uma organização formal que pretende a eficiência } \\
\text { máxima por meio de uma gestão racional. }\end{array}$ \\
\hline Ad-hocracia ${ }^{\mathrm{b}}$ & $\begin{array}{l}\text { Estrutura fortemente orgânica, com a menor incidência } \\
\text { possível de formalismos ou burocracias. Consiste em } \\
\text { equipas de especialistas, onde a procura de soluções } \\
\text { inovadoras para os problemas é levada a cabo através de } \\
\text { grupos de trabalho pluridisciplinares, descentralizados, } \\
\text { pouco formalizados e fracamente hierarquizados. }\end{array}$ \\
\hline $\begin{array}{l}\text { Imagem de } \\
\text { Clã c }\end{array}$ & $\begin{array}{l}\text { Entende as organizações como "associações íntimas de } \\
\text { pessoas empenhadas numa atividade econômica, mas } \\
\text { interligadas por uma variedade de laços" (OUCHI, } \\
\text { 1987:86) e aparece como uma tentativa de distinguir-se } \\
\text { da imagem de mercado e das burocracias formalizadas } \\
\text { ao intentar veicular uma visão mais humanista e coletiva } \\
\text { da organização empresarial. Caracteriza-se generica- } \\
\text { mente por uma convergência de metas, por papéis não } \\
\text { especializados, por controlos interiorizados e implícitos, } \\
\text { por interesses holísticos e por uma avaliação difusa. }\end{array}$ \\
\hline $\begin{array}{l}\text { Imagem de } \\
\text { Mercado }^{c}\end{array}$ & $\begin{array}{l}\text { Apresenta-se como contraponto ao modelo burocrático } \\
\text {-racional essencialmente pela convocação de elementos } \\
\text { do discurso econômico próprios para esclarecer a relação } \\
\text { do meio com a estratégia e a estrutura das organizaçôes } \\
\text { e pela exigência, ao nível da organização, de uma maior } \\
\text { flexibilidade estrutural e funcional. Por um lado, não } \\
\text { perde de vista a eficiência, as políticas de diferenciação, } \\
\text { as vantagens concorrenciais e a economia de custos e, } \\
\text { por outro, veicula a ideia da soberania do indivíduo } \\
\text { dotado de poder e liberdade de escolha. }\end{array}$ \\
\hline
\end{tabular}

Fonte: Adaptado de Caixeiro (2013) ${ }^{\mathrm{a}}$, Cunha et al. (2007) ${ }^{\mathrm{b}}$ e Estevão (1998) ${ }^{\mathrm{c}}$. 
Observa-se que a cultura de uma organização está em permanente mudança, "perspectivada como um processo de construção e reconstrução permanente, protagonizada por actores em interacção dinâmica com o social e organizacional" (TORRES, 2003, p. 98), o que reflete a relevância de se interpretar estas manifestações no contexto específico onde ocorrem, partindo das diferenças e conflitos ali identificados e percepcionadas pelos presentes.

À vista da necessidade de preenchimento de possíveis lacunas ainda existentes, mister avocar os estudos de Ferreira e Torres (2012), onde propõem traçar o perfil-tipo de liderança do diretor escolar, com base no estilo de gestão e liderança em contexto escolar.

Figura 2: Estilos de gestão e liderança em contexto escolar.

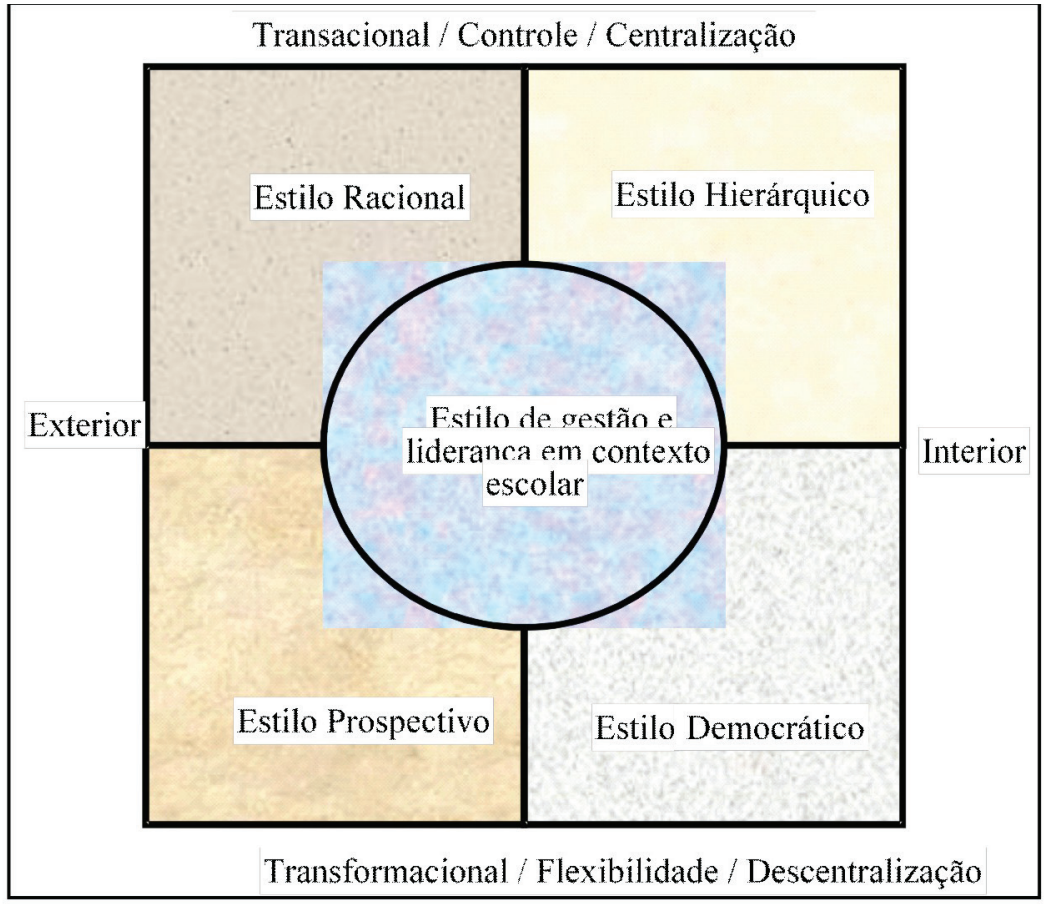

Fonte: Adaptado de Ferreira e Torres (2012, p. 93).

Nesse sentindo, observa-se que o eixo vertical representa a estrutura (formal) ou a ação (informal) da organização, assim como o eixo horizontal remete seu foco para a localização externa (contexto 
societal) ou interna (organização) dos fatores intervenientes no desenvolvimento cultural da organização escolar. Clarificando, o quadro a seguir sumariza as características predominantes dos estilos de liderança gestionária, no entendimento de Ferreira e Torres (2012):

Quadro 5: Características dos estilos de liderança gestionária escolar.

\begin{tabular}{|l|l|}
\hline $\begin{array}{l}\text { Estilos } \\
\text { de gestão }\end{array}$ & Características \\
\hline Racional & $\begin{array}{l}\text { Privilegia a centralização do poder, a organização hierárqui- } \\
\text { ca das estruturas e do controle da organização através de } \\
\text { regras de comportamento/ação definidas previamente, valo- } \\
\text { rizando a eficácia e a racionalização dos recursos. Assume-se } \\
\text { como autoridade, orientando os membros da organização } \\
\text { para a competição interna, bem como com outras organiza- } \\
\text { ções. } \\
\text { Tributário ao modelo burocrático weberiano, é regulado pe- } \\
\text { las regras formais relacionadas com a dinâmica burocrática } \\
\text { da organização (perspectiva integradora) e pelas regras não } \\
\text { formais produzidas no contexto escolar, que podem com- } \\
\text { plementar ou constituir-se como alternativa em relação às } \\
\text { formais (perspectiva diferenciadora). } \\
\text { Caracteriza-se pela previsibilidade e atitudes de conservado- } \\
\text { rismo, apostando na coordenação e manutenção da organi- } \\
\text { zação sem perspectivas de mudanças. } \\
\text { Revela a importância do papel dos atores organizacionais } \\
\text { na produção da sua cultura, mediadas pelas trajetórias de } \\
\text { socialização extraescolar vivenciadas pelos atores, bem como } \\
\text { pelo genótipo cultural da comunidade/meio. } \\
\text { A imagem do líder, estes os atores são incentivados a toma- } \\
\text { rem iniciativas e correrem riscos, promovendo uma identifi- } \\
\text { cação com a organização e a comunidade local. } \\
\text { Perspectivado como um facilitador ou colaborador que age } \\
\text { no sentido de promover a participação de todos os atores } \\
\text { organizacionais nos processos decisórios, respeitando as } \\
\text { autonomias individuais e do grupo. Logo, os objetivos da } \\
\text { organização são determinados por consenso. Enfatiza a cen- } \\
\text { tralidade da ação humana (agência) dentro da organização, } \\
\text { no processo de construção da cultura organizacional. }\end{array}$ \\
\hline
\end{tabular}

Fonte: Adaptado de Ferreira e Torres (2012). 
Logo, resta esclarecido que compreender a escola como organização demanda uma análise cuidadosa de sua história, seu contexto social e suas especificidades políticas e estratégicas, seus recursos humanos e materiais, assim como seus processos didáticos e da própria gestão, considerando instituição de ensino como uma unidade social artificialmente construída (CAIXEIRO, 2013; CUNHA et al., 2007; ESTEVÃO, 1998; MARZANO, 2005; TORRES, 2003).

\section{ESTUDO EMPÍRICO}

\subsection{Metodologia da Pesquisa}

A investigação pretendeu analisar e compreender a liderança como fator importante para o sucesso da gestão de uma escola privada, com predominante influência organizacional internacional.

Apesar de os estudos sobre o fenômeno da liderança e do julgamento moral possuírem grande tradição de ocorrerem sob uma perspectiva epistemológica positivista (STENTZ et al., 2012), elegeu-se a tipologia mista, quantitativa e qualitativa, na forma de um estudo de caso, como a mais adequada para o contexto educacional.

Com o propósito de balizar os trabalhos, relava destacar o ensinamento de Silvestre e Silvestre (2012, p.50), onde se observa na revisão da literatura a oportunidade de se "identificar problemas que são importantes para a comunidade científica, que vão ao encontro do mundo real e que ainda não foram resolvidos", sendo sintetizados na seguinte pergunta de partida: De que forma a prática da liderança contribui para o sucesso da gestão escolar?

A partir desta identificação, definiu-se os objetivos específicos e os procedimentos metodológicos que viabilizariam seu cumprimento, conforme quadro a seguir: 
Quadro 6: Relação de objetivos específicos versus procedimentos metodológicos.

\begin{tabular}{|c|c|}
\hline Objetivo específico & Procedimento metodológico \\
\hline $\begin{array}{l}\text { 1. Compreender a forma como é } \\
\text { exercida a liderança na organização } \\
\text { escolar escolhida para o estudo de } \\
\text { caso. }\end{array}$ & $\begin{array}{l}\text { Análise qualitativa da entrevista } \\
\text { com a Diretora da instituição de } \\
\text { ensino escolhida para o estudo } \\
\text { de caso. }\end{array}$ \\
\hline $\begin{array}{l}\text { 2. Identificar o(s) estilo(s) de li- } \\
\text { derança predominante da direção } \\
\text { escolar. }\end{array}$ & $\begin{array}{l}\text { Aplicação de testes estatísticos } \\
\text { básicos, de acordo com os proce- } \\
\text { dimentos do framework Multifactor } \\
\text { Leadership Questionnaire (MLQ). }\end{array}$ \\
\hline $\begin{array}{l}\text { 3. Conhecer a percepção e as ex- } \\
\text { pectativas dos agentes educativos } \\
\text { sobre o modelo de liderança e como } \\
\text { a sua gestão escolar podem afetar o } \\
\text { sucesso institucional. }\end{array}$ & $\begin{array}{l}\text { Análise qualitativa dos dados } \\
\text { recolhidos por meio do MLQ, } \\
\text { consubstanciado pela apresenta- } \\
\text { ção do “estado da arte” dos es- } \\
\text { tudos sobre excelência de gestão } \\
\text { escolar. }\end{array}$ \\
\hline
\end{tabular}

Fonte: elaboração própria.

Diante dos objetivos traçados e finalizando a fase de planejamento da investigação, as seguintes hipóteses foram propostas:

H1 - O estilo de liderança assumido pela direção da escola tem afetado a atuação dos agentes educadores, em prol da eficácia da gestão escolar; e

H2 - A liderança e os processos administrativos adotados são fatores de sucesso relevantes na gestão escolar.

Segundo Pacheco (1995, p. 9), uma investigação no contexto educacional caracteriza-se por ser "uma atividade de natureza cognitiva, que consiste num processo sistemático, flexível e objeto de indagação e que contribui para explicar e compreender os fenômenos educativos", o que permite pressupor a presença de pressupõe-se a sistematização, o rigor científico e a adequação do objeto em análise como condições primeiras na definição da metodologia.

No contexto da abordagem qualitativa, segundo Tuckman (2000), a investigação se inscreve a partir da aproximação e indagação da realidade social e educativa, enfatizando as especificidades, 
origens, causas e consequências de um fenômeno. Portanto, foi proposta a utilização da pesquisa bibliográfica, sitográfica e análise documental como suporte teórico dos estudos, assim como a recolha e tratamento de dados complementares através do inquérito por entrevista semiestruturada à direção da escola. Sendo assim, a amostragem da realidade e a praticidade dos fatos em questão permitem a construção de uma lógica no estudo e, na utilização de uma linguagem mais acessível, a possibilidade do surgimento de outras vertentes de investigação desta forma de liderança.

Já no contexto da abordagem quantitativa, privilegiou-se a quantificação e as relações de causalidade, o que justifica a aplicação de inquéritos por questionário a fim de ampliar o campo de pesquisa e assim facilitar a posterior triangulação de dados. Assenta-se o método estatístico básico para a caracterização da amostra, coleta, tratamento e apresentação dos dados coletados por meio de inquérito por questionário aos professores e coordenadores da escola em estudo.

A operacionalização da etapa de coleta e tratamento dos dados ocorreu por meio da grelha de observação e aplicação do questionário adaptado do clássico framework de Bass e Avolio (2004), denominado Multifactor Leadership Questionnaire - MLQ, utilizando como plataforma o Google Forms para sua confecção e aplicação on-line.

Nesse sentido, oportuno esclarecer que a escolha da estratégia de aplicação do método de coleta de dados deve sempre atentar para aspectos como "custo, tempo e forma, para que venha a garantir uma taxa de resposta aceitável ao estudo" (FREITAS et al. 2000, p. 107), o que valida a escolha da aplicação do framework MLQ, de forma on-line. Posteriormente, devido à simplicidade do tratamento estatístico dos dados, utilizou-se o programa Microsoft Excel para a resolução, clarificação de dados e apresentação gráfica das informações geradas.

Adicionalmente, considerando os objetivos da investigação e a relevância apresentados, a opção por uma pesquisa quali-quantitativa, na forma de um estudo de caso único, representou estratégia mais adequada, em especial ao se propor questões do tipo "como" e "por que", recomendadas para situações onde o investigador tem pouco controle sobre os acontecimentos e quando o foco se encontra 
em fenômenos contemporâneos, inseridos em algum contexto da vida real (YIN, 2015).

\subsection{Contextualização}

Esta investigação limita sua amostra a um estudo de caso em uma escola privada, estruturada e gerenciada sob o enfoque de uma cultura organizacional internacional, situada na região norte do Portugal e que apresenta resultados compatíveis à efetiva aplicação de boas práticas de gestão, desenvolvidas neste ramo da sociedade, por exemplo, através de muitos prêmios de destaque dos seus alunos, tanto nacionalmente como internacionalmente, assim como a credibilidade que a organização possui junto a seus pares.

Logo, o estudo buscou diagnosticar a forma como essa liderança é exercida na percepção e expectativa de seus atores, assim como seu impacto como fator diferencial para o sucesso de sua gestão, medidos não só pelos resultados dos alunos, mas pelo seu desenvolvimento pessoal e social, motivação e comprometimento de professores e colaboradores, o compromisso de todos pelo bem-estar, qualidade da aprendizagem e o contributo da organização escolar para toda a sociedade.

A análise desta ampla gama de dados ocorreu, fundamentalmente, sob um enfoque qualitativo, de forma indutiva, compreensiva e holística, pois a interpretação de todo o contexto organizacional e a realidade profunda dos fatos são dados que permitiram sustentar a confirmação das hipóteses inicialmente formuladas, cumprindo assim os objetivos propostos para a investigação.

Entretanto, há que se considerar a eficácia do aspecto quantitativo esperado com a aplicação dos questionários aos professores e coordenadores da organização, uma vez que permite "operacionalizar conceitos, estabelecer relações de causalidade, generalizar as conclusões do estudo à população" (RODRIGUES, 2012, p. 172) por se tratar de processos estatísticos que permitem "obter de conjuntos complexos, representações simples e constatar se essas verificações simplificadas têm relação entre si" (MARCONI; LAKATOS, 2003, p. 108).

Sendo assim, buscou-se em sua ampla representatividade a ratificação dos estudos que defendem a importância da liderança para o sucesso da gestão escolar (CAIXEIRO, 2013; GARZA et al., 2014; 
LEITHWOOD; HARRIS; HOPKINS, 2008; YANG, 2014), reforçando o entendimento de que a utilização de uma metodologia mista foi relevante para esta investigação. Nesta investigação, privilegiou-se a abordagem qualitativa a partir do inquérito por entrevista à diretora da instituição de ensino escolhida para o estudo de caso, complementada por dois questionamentos subjetivos e opcionais aplicados aos docentes.

A entrevista tornou possível realizar uma comparação da percepção da entrevistada sobre o seu modo de entender e exercer a liderança com a percepção recolhida junto aos docentes, ou seja, a percepção de seus seguidores neste complexo processo de bem gerir uma instituição de sucesso.

Já a abordagem quantitativa foi realizada com o objetivo de estudar os estilos de liderança adotados nesta instituição de ensino privada na região norte de Portugal. Na concepção de Rodrigues (2012, p. 172), uma investigação quantitativa busca "operacionalizar conceitos, estabelecer relações de causalidade, generalizar as conclusões de seu estudo à população e permitir que o estudo realizado seja passível de ser reproduzido".

\subsection{MLQ}

O Multifactor Leadership Questionnaire (MLQ) é um instrumento consagrado de recolha de dados, desenvolvido por Bass e Avolio, e que tem for finalidade identificar os estilos de liderança presentes em uma organização por meio da avaliação dos comportamentos do líder na percepção de seus liderados (ANTONAKIS, 2001; BASS; AVOLIO, 2004; TEJEDA; SCANDURA; PILLAI, 2001), sintetizados nas seguintes áreas de atuação (Quadro 7).

Oportuno o entendimento de Camões (2012), segundo o qual a utilização de inquéritos por questionário se justifica, principalmente, quando o objetivo é medir a percepção ao nível individual, mesmo sendo necessária a posterior análise estatística dos dados obtidos. Nesse sentido, justifica-se a escolha por um modelo consagrado em estudos do gênero, validado ao próprio contexto social de Portugal, a partir da análise de artigos e estudos acadêmicos sobre o tema (AZEVEDO; CARVALHO, 2014; GÓIS, 2011; GONÇALVES, 2011; INOCÊNCIO, 2013; INOCÊNCIO; RESENDE, 2014). 
Quadro 7: Características das áreas de atuação dos componentes do $M L Q$.

\begin{tabular}{|c|c|c|}
\hline & $\begin{array}{l}\text { Área de } \\
\text { atuação }\end{array}$ & Características \\
\hline \multirow{4}{*}{ 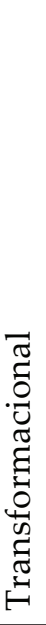 } & $\begin{array}{l}\text { Atitude de } \\
\text { Influência } \\
\text { Idealizada }\end{array}$ & $\begin{array}{l}\text { O líder escolhe comportamentos que ativam fortes emo- } \\
\text { ções nos seguidores, promovem a confiança e identificação } \\
\text { destes com ele, influenciam os seus ideais e os valores. }\end{array}$ \\
\hline & $\begin{array}{l}\text { Motivação } \\
\text { Inspiracional }\end{array}$ & $\begin{array}{l}\text { O líder comunica uma visão apelativa, usa símbolos para } \\
\text { incrementar o esforço dos seguidores, atua como um mo- } \\
\text { delo de comportamento, instila otimismo. }\end{array}$ \\
\hline & $\begin{array}{l}\text { Estimulação } \\
\text { Intelectual }\end{array}$ & $\begin{array}{l}\text { O líder estimula nos seguidores a tomada de consciência } \\
\text { dos problemas, dos seus próprios pensamentos e imagi- } \\
\text { nação. Ajuda-os a reconhecer as suas próprias crenças e } \\
\text { valores. }\end{array}$ \\
\hline & $\begin{array}{l}\text { Consideração } \\
\text { Individual }\end{array}$ & $\begin{array}{l}\text { O líder atende às necessidades de desenvolvimento dos } \\
\text { seguidores, apoia-os, encoraja-os, treina-os, tenta desen- } \\
\text { volver o seu potencial, fornece-lhes feedback, delega-lhes } \\
\text { responsabilidades. }\end{array}$ \\
\hline \multirow{2}{*}{ 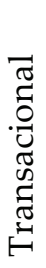 } & $\begin{array}{l}\text { Recompensa } \\
\text { por Objetivos } \\
\text { Atingidos }\end{array}$ & $\begin{array}{l}\text { O líder clarifica para o seguidor o que este deve fazer } \\
\text { para ser recompensado pelo esforço. }\end{array}$ \\
\hline & $\begin{array}{l}\text { Gestão por } \\
\text { Exceção Ativa }\end{array}$ & $\begin{array}{l}\text { O líder monitora o desempenho dos seguidores e adota } \\
\text { ações corretivas se eles não alcançam os padrões estabele- } \\
\text { cidos. }\end{array}$ \\
\hline \multirow{2}{*}{ 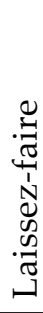 } & $\begin{array}{l}\text { Gestão por Ex- } \\
\text { ceção Passiva }\end{array}$ & $\begin{array}{l}\text { O líder assume uma atitude passiva, não chamando a } \\
\text { atenção para as falhas detectadas, não tomando atitudes } \\
\text { para que tal não aconteça. É pouco atuante e só age quan- } \\
\text { do os problemas se tornam crônicos. }\end{array}$ \\
\hline & $\begin{array}{l}\text { Ausência de } \\
\text { Liderança }\end{array}$ & $\begin{array}{l}\text { O líder assume uma atitude de inatividade, evitando to- } \\
\text { mar decisões, não assumindo as suas responsabilidades e } \\
\text { não exercendo a sua moralidade. É um líder ausente. }\end{array}$ \\
\hline \multirow{3}{*}{ 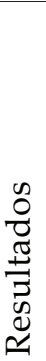 } & Eficácia & $\begin{array}{l}\text { A ação do líder vai de encontro às necessidades indivi- } \\
\text { duais e às necessidades da organização. Representa a } \\
\text { organização que dirige. }\end{array}$ \\
\hline & Satisfação & $\begin{array}{l}\text { A ação do líder desperta satisfação nos seguidores e motiva } \\
\text {-os para melhores desempenhos. O estilo deve ser adequa- } \\
\text { do, uma vez que gera bem-estar e vontade de mudança. }\end{array}$ \\
\hline & Esforço-extra & $\begin{array}{l}\text { O líder desenvolve os seguidores e leva-os a melhores } \\
\text { desempenhos. }\end{array}$ \\
\hline
\end{tabular}

Fonte: Adaptado de Bass e Avolio (2004) e Cunha e Costa (2008). 
Sendo assim, a finalidade da aplicação adaptada do MLQ é determinar o modo como os docentes percepcionam a prática da liderança na instituição de ensino em análise, ou seja, o(s) estilo(s) de liderança da administração no dia a dia da organização sob os aspectos transformacional, transacional e "laissez-faire" e seus resultados na gestão escolar, estes expressos nos fatores (i) eficácia, (ii) satisfação e (iii) esforço-extra.

\section{Figura 3: Estilo de liderança segundo o Multifactor Leadership Questionnaire (MLQ) / 3}

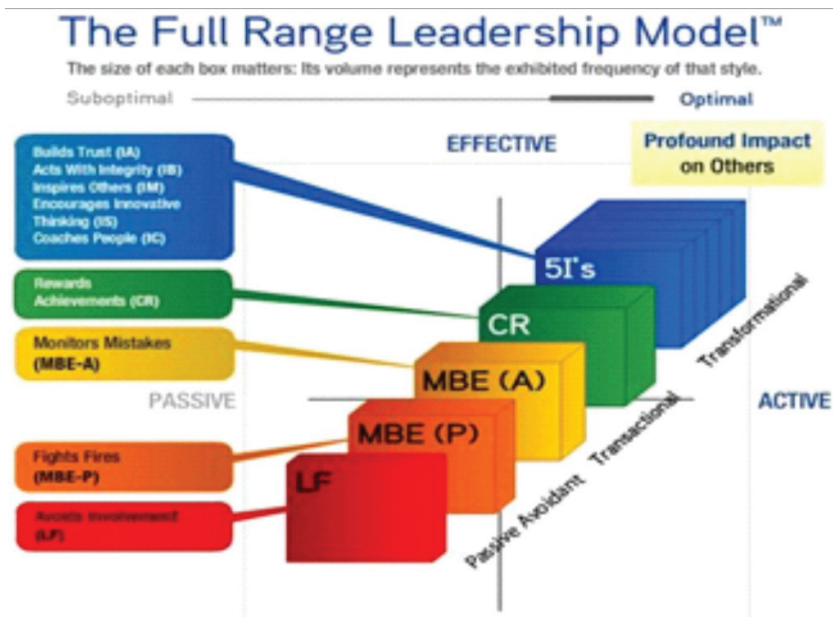

Fonte: Hersey e Blanchard (1988).

${ }^{2}$ Disponível em: http://elijahconsulting.com/wp-content/uploads/2013/01/FRLM-Graphic_1.jpg

${ }^{3}$ Nossa tradução para a legenda do gráfico MLQ:

\begin{tabular}{|l|l|l|}
\hline \multirow{4}{*}{ Transformacional } & IA - Influence Attitudes & Atitude de Influência Idealizada \\
\cline { 2 - 3 } & IB - Influence Behavior & Comportamento de Influência Idealizada \\
\cline { 2 - 3 } & IM - Inspirational Motivation & Motivação Inspiracional \\
\cline { 2 - 3 } & IS - Intellectual Stimulation & Estimulação Intelectual \\
\cline { 2 - 3 } & IC - Individual Consideration & Consideração Individual \\
\hline \multirow{3}{*}{ "Laissez-faire” } & CR - Contingent Reward & Recompensa por Objetivos Atingidos \\
\cline { 2 - 3 } & MBE (A) Management by Exception Active & Gestão por Exceção Ativa \\
\hline & MBE (P) Management by Exception Passive & Gestão por Exceção Passiva \\
\cline { 2 - 3 } & LF - Laissez Faire & Ausência de Liderança \\
\hline
\end{tabular}


Releva destacar que o questionário, adaptado do MLQ, foi composto por 52 perguntas, sendo cinco primeiras com o objetivo de caracterizar um perfil de respondente, duas perguntas subjetivas e de livre expressão (opcional) e 45 sob a forma de análise de frequência, ou seja, uma escala do tipo Likert escalonadas em cinco opções de 0 a 4 .

Especificamente em relação às 45 perguntas do MLQ, estas são agrupadas em 12 áreas de atuação (Quadro 8).

Quadro 8: Área de atuação, componentes e perguntas do MLQ.

\begin{tabular}{|c|c|c|c|c|c|}
\hline \multirow{2}{*}{ Área de atuação } & \multicolumn{5}{|c|}{$\begin{array}{l}\text { Perguntas do Multifactor Leadership Questionnaire } \\
\text { (MLQ) }\end{array}$} \\
\hline & \multicolumn{2}{|c|}{$\begin{array}{l}\text { Transformacio- } \\
\text { nal }\end{array}$} & $\begin{array}{l}\text { Transa- } \\
\text { cional }\end{array}$ & Laissez-faire & Resultados \\
\hline \multicolumn{2}{|c|}{$\begin{array}{l}\text { 1. Atitude de Influência Idealizada } \\
\text { IIA - Idealized Influence Attitudes }\end{array}$} & $\begin{array}{l}15,23,26 \\
\text { e } 30\end{array}$ & - & - & - \\
\hline \multicolumn{2}{|l|}{$\begin{array}{l}\text { 2. Comportamentos de Influência } \\
\text { Idealizada } \\
\text { IIB - Idealized Influence Behavior }\end{array}$} & $\begin{array}{l}11,19,28 \\
\text { e } 39\end{array}$ & - & - & - \\
\hline \multicolumn{2}{|l|}{$\begin{array}{l}\text { 3. Motivação Inspiracional } \\
\text { IM - Inspirational Motivation }\end{array}$} & $\begin{array}{l}14,18,31 \\
\text { e } 41\end{array}$ & - & - & - \\
\hline \multicolumn{2}{|l|}{$\begin{array}{l}\text { 4. Estimulação Intelectual } \\
\text { IS - Intellectual Stimulation }\end{array}$} & $\begin{array}{l}7,13,35 \\
\text { e } 37\end{array}$ & - & - & - \\
\hline \multicolumn{2}{|l|}{$\begin{array}{l}\text { 5. Consideração Individual } \\
\text { IC - Individual Consideration }\end{array}$} & $\begin{array}{l}20,24,34 \\
\text { e } 36\end{array}$ & - & - & - \\
\hline \multicolumn{2}{|c|}{$\begin{array}{l}\text { 6. Recompensa por Objetivos Atingidos } \\
\text { CR - Contingent Reward }\end{array}$} & - & $\begin{array}{l}6,16,21 \\
\text { e } 40\end{array}$ & - & - \\
\hline \multicolumn{2}{|c|}{$\begin{array}{l}\text { 7. Gestão por Exceção Ativa } \\
\text { MBEA - Management by Exception } \\
\text { Active }\end{array}$} & - & $\begin{array}{l}9,27,29 \\
\text { e } 32\end{array}$ & - & - \\
\hline \multicolumn{2}{|l|}{$\begin{array}{l}\text { 8. Gestão por Exceção Passiva } \\
\text { MBEP - Management by Exception } \\
\text { Passive }\end{array}$} & - & & $\begin{array}{l}8,17,22 \\
\text { e } 25\end{array}$ & - \\
\hline \multicolumn{2}{|l|}{$\begin{array}{l}\text { 9. Ausência de Liderança } \\
\text { LF- Laissez-faire }\end{array}$} & - & - & $\begin{array}{l}10,12,33 \\
\text { e } 38\end{array}$ & - \\
\hline \multicolumn{2}{|l|}{$\begin{array}{l}\text { 10. Eficácia } \\
\text { Effectivness }\end{array}$} & - & - & - & 42,45 e 48 \\
\hline \multicolumn{2}{|l|}{$\begin{array}{l}\text { 11.Satisfação } \\
\text { Satisfaction }\end{array}$} & - & - & - & 43,46 e 49 \\
\hline \multicolumn{2}{|l|}{$\begin{array}{l}\text { 12. Esforço extra } \\
\text { Extra Effort }\end{array}$} & - & - & - & 44,47 e 50 \\
\hline
\end{tabular}

Fonte: Adaptado de Bass e Avolio (2004). 
As 12 áreas de atuação correspondem aos quatro componentes de análise: (i) liderança transformacional - com cinco áreas de atuação; (ii) liderança transacional - com duas áreas de atuação; (iii) "laissez-faire" - com duas áreas de atuação; e (iv) resultados da gestão - com três áreas de atuação.

Sendo assim, após a coleta dos questionários, edita-se e tratam-se os dados por meio de uma proposta de análise estatística básica dos resultados, introduzindo-os no programa Microsoft Excel para a resolução, simplificação e apresentação gráfica das informações geradas.

A caraterização dos respondentes se faz por meio do cálculo de frequências relativas e absolutas. Posteriormente, a identificação do estilo predominante na instituição, assim como os próprios resultados para a gestão, é calculada por meio de medidas de tendência central, isto é, por meio da média do estilo de liderança e dos resultados, percepcionados pelos respondentes, corroborando com a simplicidade e efetividade do modelo escolhido para esta investigação.

\section{APRESENTAÇÃo E disCuSSÃo dos RESUlTAdos}

\subsection{Descrição da Amostra}

O Colégio Internacional de Braga (CLIB), criado em 1999 para fornecer uma educação equilibrada e de alta qualidade aos alunos portugueses e à comunidade internacional de Braga, tem seus currículos do ensino pré-escolar, primeiro e segundo ciclos, baseados no currículo britânico, com alguns ajustamentos, devido à diversidade de nacionalidades dos alunos.

Os alunos são preparados para os exames internacionais IGCSE (International General Certificate of Secundary Education) e diploma AICE (Advanced International Certificate Education), onde os programas de estudo têm equivalência horizontais ao sistema educativo português e o exame final AICE, onde os alunos do $12^{\circ}$ ano, através da Universidade de Cambridge, Reino Unido, têm uma equivalência a qualquer agrupamento de ensino secundário português, pela Portaria 779/98 de 16 de setembro. Por conseguinte, adquirem uma equivalência, tanto a nível nacional como internacional, podendo, 
assim, dar continuidade aos seus estudos universitários em Portugal ou no estrangeiro, no final do $12^{\circ}$ ano, conforme as opções pessoais e familiares.

Tendo o inglês como "língua oficial", logo utilizada na maior parte das disciplinas, sua fluência e correção são estimuladas desde o primeiro contato dos novos alunos, momento o qual a parceria escola-família se torna imprescindível na mudança cultural deste jovem aprendiz.

O CLIB se integra no projeto de rede, iniciado no Colégio Luso-Internacional do Porto e continuado no Colégio Luso-Internacional do Centro (Marina Grande) e, devido a esta ligação, em redes de escolas internacionais como o ECIS (European Council of International Schools).

Em seu Programa Educativo, destacam-se nove princípios pedagógicos fundamentais: (i) Excelência Acadêmica; (ii) Aprender a Aprender; (iii) Aprendizagem em Equipa; (iv) Diversidade e Educação Transcultural; (v) Desenvolvimento Ético e Moral; (vi) Interesses e Necessidades Individuais; (vii) Interesses e Necessidades Individuais; (viii) Tomada de Decisões Participativas; e (ix) Expressões Artísticas.

Seu corpo docente é composto por professores portugueses e outros oriundos de vários países, pelo que sua diversidade étnica e cultural permite enriquecer o tecido social do CLIB e proporcionar um caráter multicultural e multilíngue ao seu contexto organizacional. Outrossim, dentro do aspecto de multiculturalismo, desenvolvimento cognitivo e formação de líderes para uma nova e dinâmica sociedade, o CLIB realiza diversos projetos.

\subsection{Análise do MLQ}

Após a autorização da direção do CLIB para a aplicação do questionário Multifactor Leadership Questionnaire (MLQ) ao corpo docente da instituição, o mesmo foi distribuído entre os meses de junho e julho de 2015. Naquele momento, o espaço amostral era de 20 professores e o inquérito foi encaminhado para o email funcional dos respondentes, nas versões inglês e português, sendo ressaltado que o mesmo foi desenvolvido na plataforma Google Forms, o que não permite, por acesso ao link específico, à identificação do respondente. 
Ao iniciar as discussões dos dados recolhidos por meio da aplicação do MLQ, faz-se necessária a devida caracterização dos 13 respondentes, o que equivale a $65 \%$ da população pesquisada, o que torna uma amostra significativa de pesquisa estatística, conforme quadro no 09.

Em destaque, a predominância de professores do sexo feminino (77\%), na faixa etária de 36 a 50 anos e com considerável habilitação acadêmica, com destaque para 36\% com título de mestre e um pós-doutorado.

Quadro 9: Caracterização dos respondentes.

\begin{tabular}{|c|c|c|c|}
\hline \multirow[b]{2}{*}{ Variáveis } & \multicolumn{3}{|c|}{ Frequências } \\
\hline & $\begin{array}{l}\text { Absoluta } \\
(\mathrm{n}=13)\end{array}$ & $\begin{array}{l}\text { Relativa } \\
(\%)\end{array}$ & $\begin{array}{l}\text { Acumulada } \\
(\%)\end{array}$ \\
\hline $\begin{array}{l}\text { Gênero a) } \\
\text { Masculino } \\
\text { Feminino }\end{array}$ & $\begin{array}{l}1 \\
10\end{array}$ & $\begin{array}{l}8 \\
77\end{array}$ & $\begin{array}{l}8 \\
85\end{array}$ \\
\hline $\begin{array}{l}\text { Faixas etárias } \\
\text { até } 35 \text { anos } \\
\text { de } 36 \text { a } 50 \text { anos } \\
\text { mais de } 50 \text { anos }\end{array}$ & $\begin{array}{l}2 \\
11 \\
0\end{array}$ & $\begin{array}{l}15 \\
85 \\
0\end{array}$ & $\begin{array}{l}15 \\
100\end{array}$ \\
\hline $\begin{array}{l}\text { Titulação acadêmica }{ }^{\text {b) }} \\
\text { Bacharel / Licenciado } \\
\text { Mestre } \\
\text { Doutor } \\
\text { PhD }\end{array}$ & $\begin{array}{l}6 \\
5 \\
0 \\
1\end{array}$ & $\begin{array}{l}46 \\
38 \\
0 \\
8\end{array}$ & $\begin{array}{l}46 \\
84 \\
84 \\
92\end{array}$ \\
\hline $\begin{array}{l}\text { Tempo de serviço na insti- } \\
\text { tuição } \\
<3 \text { anos } \\
\text { de } 3 \text { a } 6 \text { anos } \\
\text { de } 7 \text { a } 10 \text { anos } \\
>10 \text { anos }\end{array}$ & $\begin{array}{l}4 \\
3 \\
2 \\
4\end{array}$ & $\begin{array}{l}31 \\
23 \\
15 \\
31\end{array}$ & $\begin{array}{l}31 \\
54 \\
69 \\
100\end{array}$ \\
\hline $\begin{array}{l}\text { Nacionalidade portuguesa }{ }^{c} \\
\text { Sim } \\
\text { Não }\end{array}$ & $\begin{array}{l}8 \\
2\end{array}$ & $\begin{array}{l}62 \\
15\end{array}$ & $\begin{array}{l}62 \\
77\end{array}$ \\
\hline
\end{tabular}

Fonte: dados da pesquisa.

a) 2 respondentes não identificaram o gênero.

b) 1 respondente não identificou a titulação.

c) 3 respondentes não identificaram a nacionalidade portuguesa. 
No que tange ao tempo de serviço na instituição, observa-se que apenas $31 \%$ dos professores têm menos de 3 anos de serviço no colégio, ou melhor, o mesmo percentual de professores com mais de 10 anos de dedicação a uma instituição que tem apenas 15 anos de criação. Resta demonstrado que, apesar da natural rotatividade entre professores que possuem carreira em colégios internacionais, o CLIB mantém sua força laboral por período relevante.

Todavia, este dado de perfil de carreira pode ser questionado pelo fato de $62 \%$ dos respondentes serem de nacionalidade portuguesa. Em um nicho de mercado, marcado pela predominância da mobilidade entre países e pela própria população da instituição de ensino em tela ser formada por professores de outras nacionalidades, a concentração de respondentes de origem portuguesa não torna este dado de significância estatística para replicação ou maiores análises, sendo desconsiderada, a princípio, na investigação.

Quadro 10: Análise descritiva do MLQ.

\begin{tabular}{|l|l|l|l|}
\hline \multirow{2}{*}{ Estilo } & \multirow{2}{*}{ Média } & \multicolumn{3}{|l|}{ Desvio-padrão } \\
\cline { 3 - 4 } & & absoluto & relativo \\
\hline Liderança Transformacional & & & \\
IIA & 2,67 & 1,31 & $33 \%$ \\
IIB & 3,07 & 1,08 & $27 \%$ \\
IM & 2,91 & 1,08 & $27 \%$ \\
IS & 2,57 & 1,44 & $36 \%$ \\
IC & 2,41 & 1,46 & $36 \%$ \\
Liderança Transformacional & & & \\
CR & 2,52 & 1,30 & $32 \%$ \\
MBEA & 2,21 & 1,28 & $32 \%$ \\
Liderança “Laissez-faire” & & & \\
MBEP & 1,33 & 1,29 & $32 \%$ \\
LF & 1,02 & 1,38 & $34 \%$ \\
Resultados da Liderança & \multicolumn{3}{|l}{} \\
Eficácia & 2,86 & 1,19 & $30 \%$ \\
Satisfação & 2,89 & 1,14 & $29 \%$ \\
Esforço-extra & 2,99 & 1,12 & $28 \%$ \\
\hline
\end{tabular}

Fonte: dados da pesquisa. 
Após a caracterização da amostra, as respostas obtidas por meio da parte específica do questionário aplicado (MLQ) em seus valores absolutos (escala Lickert) foram utilizadas de forma segregada na sequência de análise, assim como a apresentação dos cálculos de média e desvio-padrão (absoluto e relativo), conforme quadro $\mathrm{n}^{\mathbf{0}} 10$ :

Observa-se que as variáveis que compõem tantos os estilos de liderança quanto os resultados na gestão escolar apresentam desvios-padrão que respeitam uma distribuição estatística normal perfeita, ou seja, $68 \%$ das ocorrências se concentraram na área da figura demarcada em azul escuro por um desvio-padrão (34\%) à direita e outro à esquerda da linha média (figura $\mathrm{n}^{\mathrm{o}} 04$ ). Sendo assim, estatisticamente é possível afirmar que, quanto maior a amostragem, mais uniforme as ocorrências poderão se distribuir na medida em que se afastam da média central, o que torna as distribuições normais previsíveis.

Figura 4: Distribuição Normal.

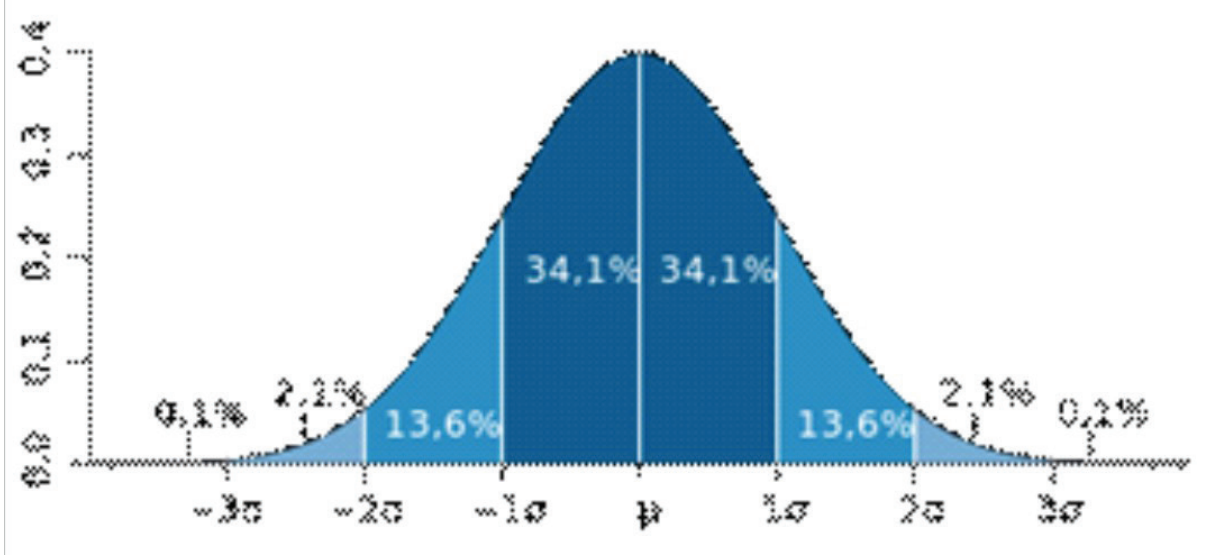

Fonte: dados da pesquisa.

Entretanto, oportuno ressaltar que quanto maior o desvio-padrão, maior a variância (dispersão) das respostas, logo mais afastados da média estarão as ocorrências extremas, o que significa que não houve uma unanimidade ou concentração da percepção dos respondentes. Sendo assim, a média dos desvios-padrão da investigação estão no linear do percentual de $34 \%$ do modelo, o que pode 
ser considerada aceitável pelo espaço contexto e amostral em tela, corroborando ao entendimento da necessidade de se complementar a análise quantitativa, com a análise qualitativa, a ser apresentada por meio do inquérito por entrevista.

\subsection{Estilo de liderança predominante}

O quadro $\mathrm{n}^{\mathrm{o}} 11$ demonstra, em termos gerais, a predominância da abordagem transformacional, com uma média de 2,73 pontos $(\mathrm{DP}=32 \%)$. Na sequência, a abordagem transacional, com média de 2,36 pontos $(\mathrm{DP}=32 \%)$ e complementa com a apresentação da abordagem "laissez-faire", com 1,17 pontos (DP=33\%). Logo, na percepção do corpo docente da instituição de ensino em estudo, a liderança transformacional obteve a maior pontuação, ratificando o resultado dos diversos estudos apresentados na revisão de literatura.

Quadro 11: Resultado da aplicação do MLQ - Estilos de Liderança.

\begin{tabular}{|l|l|l|l|}
\hline \multirow{2}{*}{ Estilos de Liderança } & Média & \multicolumn{2}{|l|}{ Desvio-Padrão } \\
\cline { 3 - 4 } & & absoluto & relativo \\
Transformacional & 2,73 & 1,27 & $32 \%$ \\
Transacional & 2,36 & 1,29 & $32 \%$ \\
“Laissez-faire” & 1,17 & 1,33 & $33 \%$ \\
\hline
\end{tabular}

Fonte: dados da pesquisa.

Contudo, pode-se afirmar que é uma predominância relativa, ao passo que também se pode constatar uma proximidade dos resultados obtidos entre as lideranças transformacional e transacional, reforçando outro aspecto relevante dos estudos, no que tange à saudável alternância de estilos comportamentais do líder, de acordo com o contexto situacional (BARRACHO, 2012; CUNHA et al., 2007; DEN HARTOG; VAN MUIJEN; KOOPMAN, 1997; HARGREAVES; FINK, 2009; PHIPPS; PIETRO, 2011; LEITHWOOD; JANTZI, 1990).

Segundo Bass e Avolio (2004), líderes transformacionais são pró-ativos, buscam identificar e otimizar as capacidades de cada seguidor, convencendo-os a atingirem altos níveis de potencial, standards morais e éticos. Por conseguinte, conseguem transpor esse desenvolvimento individual ao grupo e, posteriormente, para toda a organização, sob a forma de inovação. Sendo assim, percebe-se 
a importância dada à clarificação ao liderado daquilo que a organização entende como importante, incentivando-os que veem, por si só, as oportunidades e desafios da instituição em seu ambiente competitivo, mas de grandes realizações.

No que se refere ao estilo predominante transformacional, o que se observa na figura $\mathrm{n}^{\mathrm{o}} 5$ é que a área que apresenta uma frequência média de comportamentos em destaque é o denominado "comportamento de influência idealizada (IIB)", $\operatorname{com} 3,07$ pontos (D P = $27 \%$ ), sendo a de menor observação ou importância, na percepção dos respondentes, a área comportamental "consideração individual $(\mathrm{IC})^{\prime \prime}$, com 2,41 pontos $(\mathrm{DP}=36 \%)$.

Figura 5: Médias das áreas de atuação do Estilo de Liderança Transformacional.
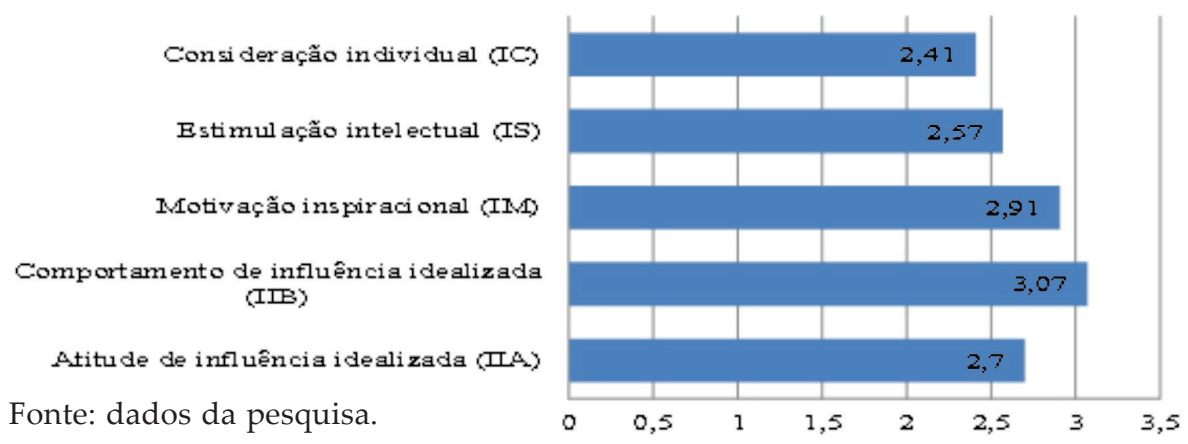

Neste sentido, é possível concluir que a liderança do CLIB adota comportamentos carismáticos, relacionados com a influência idealizada, onde o líder adota comportamentos que ativam fortes emoções em seus seguidores. A confiança e a identificação com a figura do líder influenciam os seus ideais de vida, reforçando seu empenhamento e motivação ao trabalho (CUNHA et al., 2007; FIOL; HARRIS; HOUSE, 1999; TUCKER; RUSSEL, 2004), constatado pela relevante frequência de observação dos níveis " 3 - muitas vezes" e " 4 - frequentemente" da escala estatística adotada.

Cabe também destaque o aspecto motivacional da equipe, resultado da área comportamental motivação inspiracional (IM), com média 2,91 (DP $=27 \%$ ), o que reforça o entendimento de Marzano (2005) sobre a relação direta existente entre o aspecto emocional da equipe e os níveis de realização escolar. 
Figura 6: Média das áreas de atuação do Estilo de Liderança Transacional.

Gestão por ex ceção ativa (MBEA)

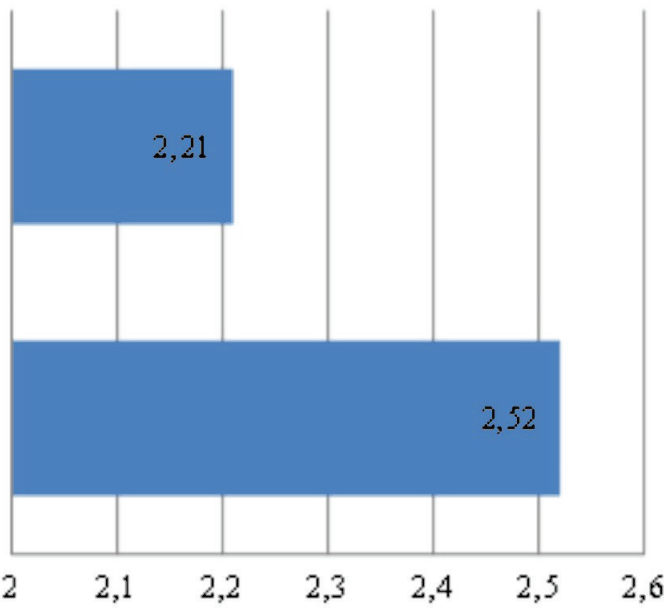

Fonte: dados da pesquisa.

Recompensa contingencial (CR)

Na sequência, sob o aspecto relacionado ao estilo de liderança transacional, observa-se pela figura $\mathrm{n}^{0} 06$ que a área de atuação em destaque é a "recompensa contingencial (CR)", com 2,52 pontos de média ( $\mathrm{DP}=32 \%)$. A área "gestão por exceção ativa (MBEA)" tem sua importância menos valorizada na concepção dos respondentes, com 2,21 pontos (DP $=32 \%$ ).

A área de atuação predominante está diretamente relacionada com a permanente clarificação, por parte do líder, dos objetivos e metas a serem cumpridas que serão devidamente recompensadas (CUNHA et al., 2007). A própria média de observação $(2,52)$, por si só, demonstra ser um comportamento que é percebido com regularidade, mas pela pouca diferença para a gestão por exceção ativa $(2,21)$, é possível constatar que ocorre em situações específicas, dentro da citada alternância situacional de gestão (HARGREAVES; FINK, 2009).

Por fim, sob o aspecto relacionado ao estilo de liderança "laissezfaire", observa-se pela figura no 07 que a área de atuação em destaque é a "gestão por exceção passiva (MBEP)", com frequência de observações comportamentais na ordem de 1,33 pontos de média (DP $=32 \%$ ). Em contrapartida, a área comportamental de "ausência de liderança (LF)" tem sua importância menos percebida na concepção 
dos respondentes, com frequência de observações comportamentais na ordem de 1,02 pontos médios ( $\mathrm{DP}=34 \%$ ).

Figura 7: Médias das áreas de atuação do Estilo de Liderança "Laissez-faire".

Gestão por ex ceção passiva (MBE $P$ )

Laissez-faire (LF)

Fonte: dados da pesquisa.

Ambas as percepções se encontram entre os níveis "1 raramente" e nível "2 - algumas vezes", o que reforça o acima indicado da alternância situacional, porém com pouca existência de um perfil laissez-faire de atuação da liderança, ou seja, de praticamente abstenção de influenciação aos colaboradores da instituição.

Mister ressaltar que um estudo de natureza social corrobora entendimentos de ordem profissional e pessoal, onde uma das funções estatísticas do desvio-padrão é exatamente buscar amenizar a análise de dados numéricos, muitas das vezes, isentos de contextualização ambiental e temporal.

Na sequência da análise dos dados obtidos por meio do MLQ, o modelo Full Range Leadership Model (BASS; AVOLIO, 2004) possibilitou quantificar a percepção do corpo docente quanto aos resultados comportamentais da equipe junto à gestão escolar, quando confrontados aos estilos de liderança adotados no dia a dia da instituição.

$\mathrm{O}$ quadro 12 demonstra que os respondentes percepcionam como principal resultado da liderança o "esforço-extra", apresentado por todos, isto é, em geral, o ambiente que envolve esta instituição 
escolar estimula seus colaboradores ao empenhamento pelo sucesso coletivo. Estudos reforçam que organizações excelentes têm líderes que definem e comunicam um rumo claro, com atitudes que unificam e motivam seus colaboradores, gerando liberdade e confiança em contextos de incerteza e mudanças constantes (EFQM, 2002; TRIGO; COSTA, 2008).

Quadro 12: Resultado da aplicação do MLQ - Resultados da liderança na gestão escolar.

\begin{tabular}{|l|l|l|l|}
\hline \multirow{2}{*}{\begin{tabular}{l|l|l|} 
Resultados na Gestão Escolar \\
Eficácia \\
(Effectioness)
\end{tabular}} & Média & \multicolumn{2}{|l|}{ Desvio-Padrão } \\
\cline { 2 - 4 } $\begin{array}{l}\text { Satisfação } \\
\text { (Satisfaction) }\end{array}$ & 2,86 & 1,19 & $30 \%$ \\
$\begin{array}{l}\text { Esforço-extra } \\
\text { (Extra Effort) }\end{array}$ & 2,89 & 1,14 & $29 \%$ \\
\hline
\end{tabular}

Fonte: dados da pesquisa.

Contudo, ressalta-se que os resultados da liderança na gestão escolar foram muito próximos em termos percentuais, em especial quando se observa os valores médios que se situam a frequência de observações das variáveis eficácia $(\mathrm{M}=2,86$ e DP $=30 \%)$ e satisfação $(\mathrm{M}=2,89$ e $\mathrm{DP}=29 \%)$, todas entre as condições de serem comportamentos de nível "2 - algumas vezes" e de nível "3 - muitas vezes". Não deixando de esclarecer a existência de divergência de opiniões significativas quando se verifica o percentual de 30\% em termos de desvio-padrão, porém, como em todas as categorias acima analisadas, a proximidade do resultado médio corrobora o entendimento da compensação e do próprio contexto social deste tipo de pesquisa.

Em síntese, os resultados apontam para uma predominância do estilo de liderança transformacional $(\mathrm{M}=2,73$ e $\mathrm{DP}=32 \%)$, porém com forte e próxima influência da liderança transacional $(\mathrm{M}=2,36$ e DP $=32 \%$ ), o que vem a reforçar o entendimento apresentado na revisão da literatura sobre o dinamismo e complexidade a que este ambiente escolar está situado, exigente de uma gestão autônoma, 
pró-ativa, criativa, flexível e colaborativa (LEITHWOOD, 1994; MARZANO, 2005).

Figura 8: Síntese do Estilo de Liderança Dominante.

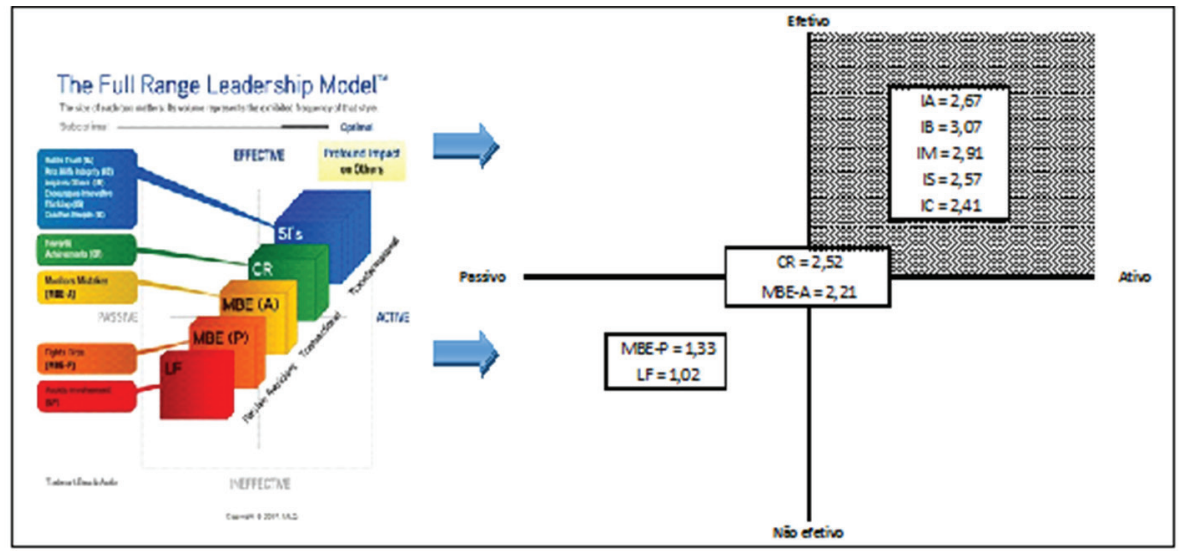

Fonte: dados da pesquisa.

Logo, a partir da percepção dos colaboradores da unidade em análise deste estudo de caso, há que se estar demonstrada a proatividade e efetividade convergentes dos estilos de liderança transformacional e transacional propostos pelos estudos do modelo Full Range Leadership de Bass e Avolio (2004), que resultam no reforço ao empenhamento, a partilha, o esforço-extra da equipe frente aos desafios do dia a dia da busca pelo sucesso da gestão escolar (CUNHA et al., 2007; LUCK, 2008).

Sendo assim, podemos confirmar a hipótese $\mathrm{n}^{\mathrm{o}} 1$ de que "o estilo de liderança assumido pela direção da escola tem afetado a atuação dos agentes educadores em prol da eficácia da gestão escolar", onde os resultados da liderança são percepcionados, em especial, pelo esforço extra demonstrado pelos seguidores, não deixando de ressaltar a proximidade e relevância da satisfação e eficácia que o ambiente desta organização impulsiona a mesma ao sucesso ali existente.

\subsection{Modelo organizacional dominante}

Na concepção de Torres (2003, p. 297), “a problemática da cultura organizacional promove uma leitura mais sólida e contextualizada 
das organizações", permitindo depreender que símbolos, hábitos, valores éticos e morais, assim como as crenças existentes são o alicerce das ações e práticas de gestão de pessoas e resultados corporativos. Logo, complementa, "ao perspectivarmos a organização como locus de cultura e de liderança, aproximamo-nos de uma concessão mais interpretativa e subjetiva, em que a cultura e a liderança, apesar de centralmente reguladas, são construídas a partir da ação dos atores" (FERREIRA; TORRES, 2012, p. 9).

Nesse contexto, em um segundo momento da investigação, face o interesse em identificar os aspectos de funcionamento da instituição de ensino e sua relação ou não com o sucesso na gestão escolar, frente a influência da liderança sob este contexto, elegeu-se o inquérito por entrevista semiestruturada e sua posterior análise de conteúdo, sob o paradigma qualitativo supramencionado.

A entrevista possibilitou uma maior interação entre o investigador e a entrevistada, por conseguinte, o acesso direto e ilimitado à informação desejada. Neste sentido, esta técnica de recolha de dados permitiu realizar uma comparação entre a percepção dos respondentes e a auto avaliação da Diretora sobre o seu modo de exercer a liderança frente a instituição de ensino que está sob a sua responsabilidade.

Esta entrevista ocorreu no dia 10 de julho de 2015, em uma sala reservada dentro do próprio colégio, em um ambiente calmo e propício para não interrupções, com a consequente obtenção de respostas que bem contextualizaram o clima organizacional e o modo de pensar e agir da entrevistada.

Na sequência, o discurso da entrevista foi analisado sob a técnica de análise de conteúdo com o interpretar, de forma controlada, as informações prestadas pela entrevistada (BARDIN, 2004). Não sendo apenas uma simples descrição de dados, buscou-se aprender com os fragmentos que correspondam a ideias particulares entre conceitos, tratados por meio da dedução lógica de conhecimentos sobre o emissor e o receptor da mensagem (BAUER; GASKELL, 2008; RICHARDSON, 2010), alicerçada na seguinte distribuição: 
Quadro 13: Estrutura da Entrevista.

\begin{tabular}{|c|c|}
\hline Legitimação da entrevista & Perguntas \\
\hline Parte 1 - Caracterização da Entrevistada & $1,2,3,4,5$ e 6 \\
\hline $\begin{array}{l}\text { Parte } 2 \text { - Contextualização da instituição de ensi- } \\
\text { no } \\
\text { Modelos e imagens organizacionais (CAIXEIRO, } \\
\text { 2013; CUNHA et al., 2007; DESPANDÉ, FARLEY \& } \\
\text { WEBSTER, 1993; ESTỄVA, 1998) } \\
\text { Cultura organizacional em contexto escolar (TOR- } \\
\text { RES, 2003) } \\
\text { Estilo de liderança gestionária escolar (FERREIRA } \\
\text { \& TORRES, 2012) }\end{array}$ & $\begin{array}{l}7,8,9,10,11,12, \\
17,18,21,22,24, \\
25,26 \text { e } 28 \\
8,10,12,14,17,18, \\
19,21,22,24,25, \\
27 \text { e } 28 \\
9,10,11,13,14,15, \\
16,18,19,20,22, \\
23,24,25,26 \text { e } 28\end{array}$ \\
\hline
\end{tabular}

Fonte: dados da pesquisa.

Por conseguinte, reforçado pelo entendimento de Richardson (2010), os seguintes objetivos básicos permearam esta fase da investigação: (i) análise das características da mensagem, sem se referir às intenções do emissor ou aos efeitos sobre o receptor; (ii) análise das causas e antecedentes, com o propósito de conhecer as condições de produção das mensagens; e (iii) análise dos efeitos da comunicação, a fim de estabelecer a influência social da mensagem.

Nos comentários iniciais da entrevistada, é possível perceber características que corroboram com as 2 (duas) áreas de atuação destaques do estilo de liderança transformacional, resultado do modelo MLQ (quantitativo) anteriormente analisado. Observa-se que a influência idealizada, segregada em atitudes e comportamentos adotados e comunicados pelo líder, atuando como um modelo de comportamento e ativando aspectos emocionais dos seguidores, obteve os índices 3,07 (IIB) e 2,67 (IIA). Adicionalmente, a motivação inspiracional, com média 2,91 (IM), tem-se o líder a apelar para símbolos, com o propósito de fomentar o esforço de todos (CUNHA et al., 2007) e, nestas áreas de percepção, destaque junto aos respondentes, já a partida, observados em trechos da entrevista como:

As pessoas têm uma ideia de que essas escolas fazem parte de uma elite só porque são mais caras e é preciso que os pais tenham um 
poder econômico para as pagar. É, de fato, uma elite se for pensar por este aspecto, em termos de conforto econômico, embora não se aplique a toda a gente. Há muitos pais que fazem esta opção abdicando de muitas outras coisas.

Colocando este aspecto de lado e sem termos qualquer tipo de complexo ou ficarmos a pensar porque somos a elite, então as pessoas acham que somos meio parvos, então vamos viver nessa parvolice (...) não, vamos provar o contrário e sim, pelo acesso que têm à formação, uma elite cultural, certamente vão ser!

O Projeto Camboja é um exemplo disso. É o extremo de tudo aquilo que eles vivem. Poderia sim ser um pouco mais cadenciado, mas não é o caso. É o limite; algo que, felizmente, não se encontra em Portugal.

Na sequência, ainda nos comentários iniciais e depois complementada pela questão $\mathrm{n}^{\mathrm{0}}$ 17, há um resumo dos chamados Award Cerimonies; assembleias de mérito onde se constata esta estratégia de motivação, não só aos alunos - pela busca da competição saudável, própria da idade e período de formação - mas também aos professores, na forma de chamá-los, todos, a compartilharem os desafios de toda a escola.

(...) quando temos as cerimônias de prêmios de mérito, que são os Award Cerimonies, o mérito não é só acadêmico. Entregamos sim o mérito acadêmico; aliás é o único momento em que divulgamos alguns resultados acadêmicos dos alunos.

A par disso, temos os demais prêmios, desde cortesia (...) passando por prêmios de inteligência emocional (...) e isso não é só reconhecer a atitude daquela pessoa, mas ficar como exemplo para os outros. Sendo assim, nestas ocasiões atribuímos prêmios desta natureza como uma forma de incentivo a este outro tipo de competência a ser desenvolvida pelos nossos alunos, que não somente a acadêmica. Assim, acreditamos que eles terão maior capacidade de lidar com outras situações que a vida lhes proporcionará, lidar com as pessoas, em especial.

O principal objetivo que eu encontro aqui é fato ser assim, a possibilidade de não ser só uma escola, ou ser mais uma escola, não ser nunca como muitas escolas estão a tornar e este sistema está publi- 
camente a ser muito criticado pelos meios de comunicação, que são as escolas que formatam os meninos para um determinado tipo de teste ou exame e vão andar sempre dentro disso e os alunos sabem responder a perguntas de exame (...) E, como já dissemos ao longo desta conversa, a formação da pessoa que não vai se conformar com as coisas, que vai querer mudar coisas, que vai querer conquistar (...) então, a visão para os alunos é essa.

E depois, tentarmos passar as mensagens de diferentes maneiras. Em alguns momentos, faço apresentação aos alunos com alguns temas, por exemplo, este ano na última Award Ceremony, iríamos falar de sucesso e um aluno, que estava no último ano, queria muito ter uma experiência de falar em público; foi então que lhe disse que iria falar sobre isso, "queres falar tu? Dou-te a minha vez para falar, pronto". Outras vezes escolhi um tema que era mais para os professores, mas preferi fazer junto dos alunos. Coisas como "vocês gostam de ser observados, queridos pelos seus professores, que o vosso professor saiba o vosso nome, das coisas que vocês gostam".

Por exemplo, esta entrevista que tenho daqui a pouco de um jornal a respeito da viagem da próxima semana para o Projeto do Camboja. Me ligaram para fazerem uma entrevista comigo, como Diretora e responsável pelos alunos e tal. Para a rádio, esta de agora, nem disse para eles, mas para os miúdos mandei-lhes logo uma mensagem dizendo que "amanhã, quem puder aparecer no CLIB pelas 10:30 horas, porque eu vou ser entrevistada por uma rádio, por telefone e eu quero passar-lhes o telefone e, que venha, pelo menos um que já tenha ido e está indo novamente e um que vai pela primeira vez, para que eles também possam conduzir por aí. E darmos a eles esta possibilidade, pois eles estão aí, envolvem-se no projeto e publicamente é reconhecido; que os meios de comunicação se interessam por saber e por divulgar esse trabalho que é deles, que eles fazem também.

Ao analisar o modelo organizacional predominante, de acordo com o quadro teórico desenvolvido junto aos estudos de Deshpandé, Farley e Webster Jr. (1993) e Estêvão (1998), pode-se destacar a imagem de clã: 


\section{Quadro 14: Conceito de Imagem de Clã.}

Imagem de Clã: Entende as organizações como "associações íntimas de pessoas empenhadas numa atividade econômica, mas interligadas por uma variedade de laços" (OUCHI 1987, p. 86) e aparece como uma tentativa de distinguir-se da imagem de mercado e das burocracias formalizadas ao intentar veicular uma visão mais humanista e coletiva da organização empresarial. Caracteriza-se genericamente por uma convergência de metas, por papéis não especializados, por controlos interiorizados e implícitos, por interesses holísticos e por uma avaliação difusa.

Fonte: Adaptado de Deshpandé, Farley e Webster Jr. (1993) e Estêvão (1998).

Observa-se a intenção da direção do colégio de tentar se distinguir de modelos tradicionais de mercado assim como do formalismo prescritivo apontados nos estudos sobre as disfunções do modelo burocrata de Max Weber. Percebe-se clareza no entendimento da forte tendência ao pré-conceito da própria sociedade para com instituições de ensino de natureza privada e internacional.

Em complemento aos já descritos trechos dos comentários iniciais, corroboram ao estilo transformacional identificado junto aos respondentes do MLQ (parte quantitativa do estudo empírico), as seguintes manifestações da entrevistada:

É um desafio muito curioso, pois as pessoas trazem suas experiências, mesmo aquelas pessoas muito jovens, trazem experiências novas e diferentes formas de fazer as coisas e isso é muito enriquecedor para a escola, enfim. E depois, aquilo que queremos ensinar aos alunos, que é a tolerância, a abertura, ou seja, aquele aluno que quer adotar outra religião ou que é de uma cultura totalmente diferente, seja lá o que for, nós temos que ser os primeiros a sermos capazes de sermos e vivermos assim, não é?.

Por exemplo, o projeto Open Minds, essa parceria com 5 países que busca exatamente isso. Ao trazermos essas crianças e elas ficarem nas casas de nossos alunos, é exatamente para que haja essa troca cultural, com todas as diferenças que possam existir. É uma ferramenta para nos ajudar as "abrir estas mentes". 
No que tange à análise da cultura em contexto escolar, conforme quadro teórico e sob o amparo dos estudos de Deshpandé, Farley e Webster Jr. (1993) e Torres (2003), destaca-se a dimensão da sociabilidade:

\section{Quadro 15: Conceito de Dimensão de Sociabilidade.}

Dimensão de Sociabilidade: Caracterizado pela predominância de regras organizacionais efetivamente atualizadas, não formais e até informais. A ênfase dominante para aspectos da cultura como variável dependente e interna ou como uma metáfora, observado por um processo de sua construção por ação e prática dos atores envolvidos, manifestada em perspectivas integradoras, diferenciadas ou multiperspectivadas.

Na perspectiva integradora, ênfase para os aspectos mais consensuais da cultura, marcado pela partilha entre os trabalhadores da organização e a figura do líder com poderes adquiridos para a eleição de seus valores e crenças. Na perspectiva diferenciadora, ênfase nas diferenciações, conflitos e antagonismos culturais emergentes, onde há o predomínio da busca de um denominador comum das várias subculturas.

Fonte: Adaptado de Torres (2003).

Corroborando ao entendimento de Torres (2003, p. 355) que "uma abordagem integrada, multidimensional e complexa das culturas organizacionais de escola possibilita um conhecimento mais profundo das realidades escolares", é possível depreender uma predominância de regras multiperspectivadas ${ }^{4}$ no contexto em tela, ou seja, em constante atualização como citado nos seguintes trechos da entrevista:

E isso vai originando muitos dos prêmios que vamos instituindo, pois nada, mas nada mesmo aqui é estático. Ok, encontramos um modelo, temos um regulamento, isto funciona e vamos manter isto e não vale a pena mudar. O que queremos é exatamente o contrário. Muitas vezes vem um professor, por exemplo, e diz: “É pena que este ano não temos um prêmio para isso". Pode não ter havido na primeira assembleia de mérito, mas pode haver na segunda. E pronto! Não há problema nenhum em introduzir naquele momento.

Regras multiperspectiva das (perspectiva integradora, diferenciadora e fragmentadora). 
(...) e em uma escola internacional tem que se ter muito cuidado, de não ser doutrinador. Porque até esta escola não pode ter uma ligação religiosa; nós acabamos por ter a festa de natal mais completa de escola que é feita aqui em Braga, que é o nosso Carol Service, porque é abrangente (...) é em uma igreja católica, porque é normalmente, nas escolas internacionais que o fazem, o fazem no templo religioso que fica mais próximo da escola e, no nosso caso é uma igreja católica que nos abre as portas. Mas não é uma cerimônia católica, pois nós não podemos influenciar nessas coisas; nós só queremos influenciar que se tornem boas pessoas, pessoas preocupadas e tal.

Por fim, a análise do estilo de liderança gestionária em contexto escolar, aplicado ao estudo de caso em tela e com amparo no quadro teórico dos trabalhos de Deshpandé, Farley e Webster Jr. (1993) e Ferreira e Torres (2012), destaca-se o estilo democrático de gestão:

Quadro 16: Conceito de Estilo de Gestão Democrático.

Democrático: Perspectivado como um facilitador ou colaborador que age no sentido de promover a participação de todos os atores organizacionais nos processos decisórios, respeitando as autonomias individuais e do grupo. Logo, os objetivos da organização são determinados por consenso. Enfatiza a centralidade da ação humana (agência) dentro da organização, no processo de construção da cultura organizacional.

Fonte: Adaptado de Deshpandé, Farley e Webster Jr. (1993) e Ferreira e Torres (2012).

Observa-se, nos seguintes trechos da entrevista, que a Diretora busca estar sempre presente no dia a dia do colégio, não somente quando da tomada de decisão. Faz parte do seu quotidiano, efetivamente vivenciar o CLIB e tentar trazer todos aqueles que queriam, de alguma forma, contribuir para o crescimento e atingimento dos desafios propostos, em especial através do exemplo e da construção de um clima organizacional que propicie a confiança de se tentar sempre sobrepor barreiras:

Na responsabilização. Impressionando as pessoas, demonstrando o que se pode fazer e trazer para fazermos juntos. Não é trazer um livro, muito giro, leiam aí e vamos ver; não é isso. Se não houver alguém 
que possa fazer aquilo comigo, pronto, faço eu. Acho sempre que se tem que tentar.

E depois fazemos sempre uma reflexão se correu bem ou não, ou vamos fazer melhor, por exemplo este próprio projeto do Camboja; poderia ser todos os anos: "quem quer vir ser professor voluntário na escolinha do Camboja?"e parou ali. Não. Tentamos que agora haja outra forma de patrocinar as crianças para prosseguir os estudos, este de formar os pais da aldeia para os negócios, agora criar a linha de microcrédito, ou seja, sempre coisas diferentes porque, precisamente, pensamos nas coisas e vimos, se teve sucesso para os alunos e queremos que continuemos assim temos de juntar mais vertentes às coisas, então esta é uma forma de avaliar, penso.

O líder sempre influencia. Seja porque faz muito, seja porque faz pouco. Seja porque é muito simpático, seja porque resmunga muito, enfim, influencia sempre. Eu acho que se tem que tentar é nem sorrir sempre nem resmungar sempre e ter, o que é o mais difícil na vida, é tentar ter um equilíbrio dessas coisas. E como dizia, se acho que um projeto é importante para a escola, vou me envolver muito nele, junto, e a forma de influenciar positivamente.

Havia um gabinete só para mim; nem pensar, eu não quero isso. Quero a equipa sempre comigo, não consigo estar a trabalhar sozinha. Dava o meu jeito se precisasse que não me interrompessem, quando fosse preciso e se fosse preciso. Prejudicava mito o trabalho e a forma como vejo o trabalho. Portanto, sei que há pessoas que posso delegar maravilhosamente, que tudo fica muito bem; outros não é bem assim , pois não cumprem os prazos e tem que estar atenta; mas o ideal é isso.

As perguntas de no .51 e 52 objetivavam permitir o respondente se expressar livremente sobre o tema em questão, possibilitando obter esta percepção não estruturada da amostra e, na mesma perspectiva qualitativa da entrevista, recolher dados menos formais. Todavia, dos 13 respondentes, apenas três respostas foram obtidas, mas que, devido seu teor de relevância e complemento a tudo o que foi discutido, são transcritas. 
The aspects mentioned are vital to give a vision and mission to what teachers do on a day-to-day basis. It instills confidence in the team ${ }^{5}$ A liderança personifica os valores da instituição. Deve representar os valores de confiança, autoridade e companheirismo.

No caso da Educação, é indispensável trabalhar em equipa, por isso a Cultura Organizacional é um aspecto importantíssimo na qualidade dos nossos desempenhos.

E no que concerne à percepção de uma ordem de importância dos conceitos de liderança, cultura organizacional e processos de gestão como componente do sucesso da instituição escolar, a marca da divergência em pesquisas desta natureza pode ser observada:
Resp. $n^{\circ}$ 1:a) Leadership; b) Management; c) Culture ${ }^{6}$
Resp. no 2:a) Liderança; b) Cultura organizacional; c) Processos de gestão

Resp. no 3:a) Cultura organizacional; b) Liderança; c) Processos de gestão

Com os depoimentos acima, ratifica-se o entendimento da confirmação da hipótese $\mathrm{n}^{\mathrm{o}} 2$ de que “a liderança e os processos administrativos adotados são fatores de sucesso relevantes na gestão escolar", tanto pelo resultado quantitativo - creditado em especial ao esforço-extra que o estilo de liderança adotado influencia no comportamento da equipe de colaboradores - quanto no resultado qualitativo do modelo organizacional predominante, onde a imagem de clã e a dimensão de sociabilidade reforçam a predominância de regras multiperspectivadas na gestão democrática desta instituição de ensino de sucesso.

Em resumo, a partir das análises qualitativas acima realizadas e sob especial amparo nos estudos de Deshpandé, Farley e Webster Jr. (1993), Estêvão (1998), Torres (2003) e Ferreira e Torres (2012), propõe-se a seguinte síntese gráfica de caracterização do modelo organizacional predominante na instituição de ensino em estudo.

\footnotetext{
5 "Os aspectos mencionados são vitais para dar uma visão e missão para aquilo que os professores fazem no dia-a-dia. Eles transmitem confiança para a equipe" (Nossa tradução para a resposta da questão n. 51 do MLQ)

6 a) Liderança, b) Processos de gestão; c) Cultura organizacional (Nossa tradução para a resposta da questão n. 52 do MLQ).
} 
Figura 9: Síntese do Modelo Organizacional Dominante.

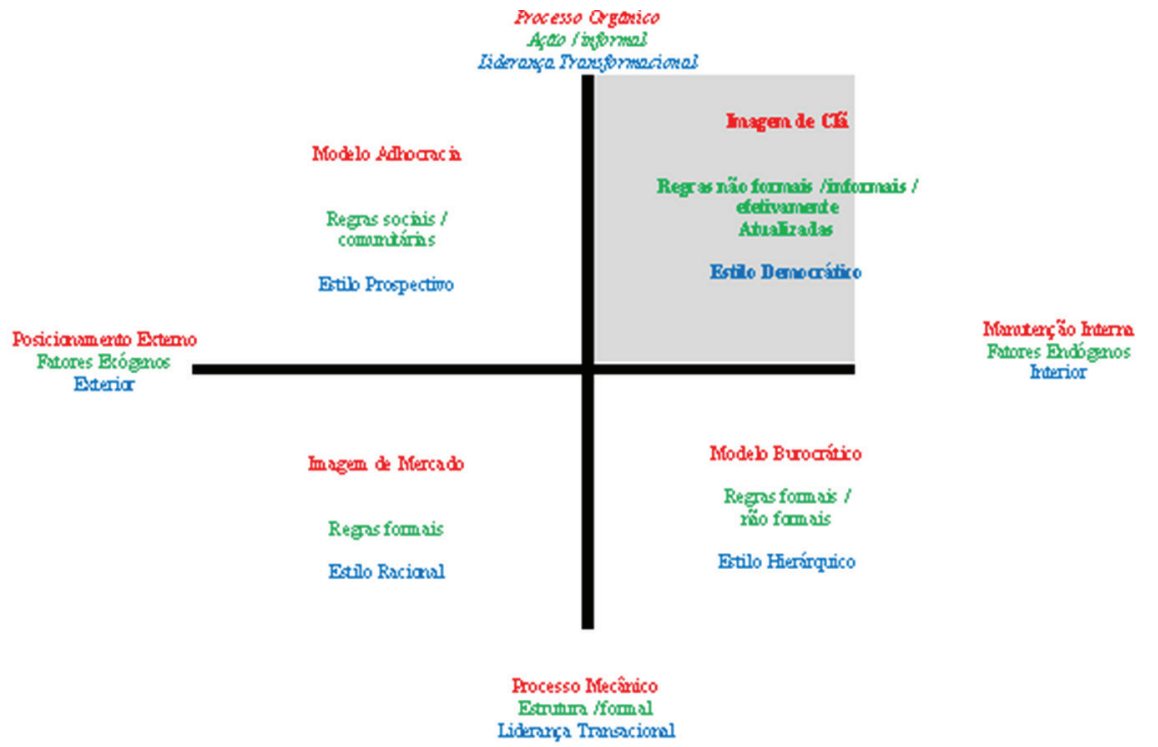

Legenda:

- Modelos e imagens organizacionais: (CAIXEIRO, 2013; CUNHA et al., 2007;

DESHPANDÉ, FARLEY; WEBSTER JR. 1993; ESTÊVÃO, 1998)

- Cultura organizacional em contexto escolar: (TORRES, 2013)

- Estilo de liderança gestionária escolar: (FERREIRA; TORRES, 2012) Fonte: dados da pesquisa.

Mister observar a própria proposta do modelo de Ferreira e Torres (2012), ao identificar no quadrante em destaque o estilo de Liderança Transformacional, com foco nos aspectos de relevância interior à organização, o que corrobora e reforça o resultado quantitativo das percepções dos respondentes ao inquérito por questionário Multifactor Leadership Questionnaire (MLQ), desenvolvido nesta investigação.

\section{CONSIDERAÇões FINAIS}

Neste momento se torna oportuno o retorno aos objetivos estabelecidos para a investigação, confrontando-os com os resultados apresentados, a fim de dar sustentabilidade à resposta da pergunta de partida: De que forma a prática da liderança contribui para o sucesso da gestão escolar? 
Destarte, como o objetivo principal desta investigação foi o de analisar o contributo da liderança para o sucesso na gestão escolar, tendo como referência de boas práticas um estudo empírico em uma escola privada da região do Minho, norte de Portugal. Finaliza-se a discussão dos resultados a partir de uma síntese conclusiva de cada um dos objetivos específicos os quais alicerçaram o trabalho:

1. Compreender a forma como é exercida a liderança na organização escolar escolhida para o estudo de caso, assim como identificar seu modelo organizacional de sucesso.

2. Identificar o(s) estilo(s) de liderança predominante da direção escolar.

3. Conhecer a percepção e as expectativas dos agentes educativos sobre o modelo de liderança e como a sua gestão pode afetar o sucesso institucional.

Inicialmente a análise crítica dos resultados do estudo nos permitiu compreender que o estilo de liderança, na percepção da equipe de docentes para com uma direção unipessoal exercida na instituição de ensino em análise, é de uma liderança predominantemente transformacional, disposta à participação consultiva, colaborativa e partilhada entre os agentes educativos, com forte abertura a projetos de inovação e visão de futuro não só para os alunos, mas para todos os membros da comunidade educacional.

Outrossim, notou-se que é um estilo gestionário democrático, a qual proporciona aos inqueridos, de uma forma relevante e equilibrada, grande satisfação, motivação e eficácia produtiva, ocasionando reflexos como aumento do empenhamento (esforço-extra) e eficiência nos projetos e desafios os quais a instituição se propõe a realizar. Todavia, há que se ressaltar a utilização ocasional de recompensas e do reconhecimento às grandes realizações dos colaboradores, reflexo direto de uma postura mais transacional, de apoio e incentivo ao processo contínuo de melhoria pessoal e profissional do indivíduo e da própria equipe, resultando em um ambiente de trabalho agradável e adequado ao contexto social.

No que tange ao modelo organizacional dominante, os resultados indiciam para a denominada imagem de clã, característica de instituições que têm presentes ao seu dia a dia uma variedade de laços interiorizados e implícitos por interesses holísticos, con- 
vergentes a metas estratégicas e na busca pelo sucesso de todos. Sendo assim, o próprio contexto permite elaborar juízos e interpretar inovações que fomentam o desenvolvimento de mecanismos isomórficos de defesa às pressões externas e ao fortalecimento de um bom ambiente de trabalho e de apoio sócio afetivo entre seus integrantes. São regras organizacionais efetivamente atualizadas, não formais e até informais, dentro de uma dimensão de sociabilidade característica de organizações que têm seu processo de construção cultural por ação e prática dos atores envolvidos, sob a integração de perspectivas integradoras, diferenciadoras e fragmentadoras (TORRES, 2003).

Afinal, aquiescente ao entendimento de Likert (1979, p. 211) de que "a escola é um empreendimento humano cujo sucesso depende dos esforços coordenados dos seus membros e que possui diversos e importantes processos e características", o estudo empírico foi eficaz na confirmação das hipóteses formuladas de que (i) o estilo de liderança assumido pela direção da escola tem afetado a atuação dos agentes educadores em prol da eficiência da gestão escolar e (ii) a liderança e os processos administrativos adotados são fatores de sucesso relevantes na gestão escolar.

Consciente que, por mais exaustivo e dedicado sejam os esforços para se cumprir um desafio desta natureza, de fato nenhum trabalho que envolva aspectos sociais de um contexto que, necessariamente, está em constante adaptação às demandas de uma sociedade global, estará terminado. Nesse sentido, não se pode deixar de relembrar o pensamento de Lima (2008, p. 410), segundo o qual "na maioria das instituições, especialmente no ensino secundário, a possibilidade de um único indivíduo, situado no topo do poder, transformar radicalmente a sua instituição é bastante diminuta". O que vem reforçar a importância do esforço-extra, do trabalho coletivo e do empenhamento motivado na participação individual de todos os colaboradores da escola.

O sucesso da gestão escolar, sob influência de um estilo de liderança predominantemente transformacional pôde ser apresentado por meio de nosso estudo empírico junto ao Colégio Luso-Internacional de Braga (CLIB), uma distinta instituição de ensino da região do norte de Portugal - reconhecida por seu forte traço 
cultural - que busca superar, por meio de sua liderança, gestão e colaboradores focados nos objetivos estratégicos disseminados, os desafios que surgem no dia a dia desta nobre missão de formar os cidadãos do mundo.

Algumas limitações ocorreram ao longo do transcurso inicial desta investigação, em especial no que tange à proposta de estratégia de recolha e análise de dados originais. Todavia, após um maior direcionamento na revisão de literatura, o desafio foi superado com a proposta da utilização de um modelo teórico mais adequado às hipóteses de trabalho, ratificando o entendimento inicial de que a apresentação de objetivos claros e frutíferos do estudo para ambas as partes, demonstrando que um trabalho desta natureza pode identificar pontos fortes e pontos fracos até então não formalmente identificados e que podem, em um futuro próximo, ser melhor analisados e agregados nas competências institucionais que a destacam em seu nicho de mercado, sustentariam as demais limitações que porventura surgissem.

Apesar da impossibilidade de imersão exclusiva ao contexto organizacional, o somatório de todos os dados recolhidos, desde a parte empírica quantitativa, por meio da aplicação do específico inquérito por questionário Multifactor Leadership Questionnaire (MLQ), complementado pela parte qualitativa, com a utilização de inquérito por entrevista à direção da instituição de ensino, propiciaram um arcabouço de informações que qualificaram e sustentaram a confirmação da hipótese (H1) o estilo de liderança assumido pela direção da escola tem afetado a atuação dos agentes educadores em prol da eficácia da gestão escolar e (H2) a liderança e os processos administrativos adotados são fatores de sucesso relevantes na gestão escolar.

Sabedores da possibilidade de incongruências entre o que se discursa e o que se pratica e pensa, fato é que há certa relevância no aprofundamento de estudos de práticas de liderança e gestão nas escolas, sempre com o foco da busca pela efetividade de suas ações, pedagógicas e administrativas.

Diante do acima exposto, o que se espera é que novos questionamentos sejam realizados sobre o tema liderança e sua influência no dia a dia do contexto escolar, uma vez que vivemos em uma sociedade dinâmica, em constante mudança e sedenta de grandes 
realizações, que exigem, pois, a formação de cidadãos preparados para sempre novos e relevantes desafios.

\section{REFERÊNCIAS}

ANTONAKIS, J. The validity of the transformational, transactional and laissez-faire leadership model as measured by the Multifactor Leadership Questionnaire (MLQ-5x), $317 \mathrm{f}$. Tese (Doutorado em Filosofia e Ciências Aplicadas à Gestão e à Decisão) - Walden University, Minneapolis, USA, 2001.

ASSOCIAÇÃO EMPRESARIAL DE PORTUGAL (AEP). Manual de boas práticas - O desafio da sucessão empresarial em Portugal, Leça de Palmeira, Portugal: Câmara de Comércio e Indústria, 2011.

AVOLIO, B.; BASS, B. M. Full range leadership development - Manual for the Multifactor Leadership Questionnaire (Form 5X), Redwood City: Mindgarden, 2002.

AZEVEDO, F.; CARVALHO, J. M. S. Estilos de liderança e motivação - estudo em IPSS's de Vila Nova de Famalicão, Studies of Organisational Management \& Sustainability, Avioso São Pedro, v. 2, n. 1, p. 36-60, 2014.

BARDIN, L. Análise de conteúdo. 3. ed., Lisboa: Edições 70, 2004.

BARRACHO, C. Liderança em contexto organizacional. Lisboa: Escolar Editora, 2012.

BASS, B. M.; AVOLIO, B. J. MLQ - Multifactor Leadership Questionnaire second edition sampler set, Redwood City, USA: Mind Garden, 2004.

BASS, B. M.; AVOLIO, B. J.; JUNG, D. I.; BERSON, Y. Predicting unit performance by assessing transformational and transactional leadership, Journal of Applied Psychology, Washington, v. 88 , n. 2, p. 207-218, 2003.

BAUER, M. W.; GASKELL, G. Pesquisa qualitativa com texto, imagem e som: um manual prático.7. ed. Petrópolis: Vozes, 2008.

BERGAMINI, C. W. Liderança: administração do sentido. 2. ed. São Paulo: Atlas, 2009.

BRYMAN, A. Charisma and leadership in organizations, London: Sage Publications, 1992.

CAIXEIRO, C. M. B. A. Liderança e cultura organizacional: O impacto do diretor na(s) cultura(s) organizacional(is) escolar(es), 677 f. Tese (Doutorado em Ciências da Educação) , Universidade de Évora, Évora, Portugal, 2013.

CAMÕES, P. J. Design de investigação. In: SILVESTRE, H. C.; ARAÚJO, J. F. (coord.) Metodologia para investigação social, Lisboa: Escolar Editora, 2012.

CHIAVENATO, I. Administração: teoria, processo e prática, 4. ed. Rio de Janeiro: Elsevier, 2007.

COSTA, J. A.; MENDES, A. N.; VENTURA, A. Liderança e estratégia nas organizações escolares, Aveiro: Universidade de Aveiro, 2000.

CUNHA, D.; COSTA, J. A. A. Liderança transformacional nas escolas estatais e privadas: um olhar centrado nas percepções dos professores, Revista Portuguesa de Investigação Educacional, n. 7. Lisboal: Universidade Católica Editora, p. 21-32, 2008. 
CUNHA, M. P.; REGO, A.; CUNHA, R. C.; CARDOSO, C. C. Manual de comportamento organizacional e gestão. 6. ed. Lisboa: Editora RH, 2007.

DEN HARTOG, D. N.; VAN MUIJEN, J. J.; KOOPMAN, P. L. Transactional versus transformational leadership: An analysis of the MLQ, Journal of Occupational and Organizational Psychology, New Jersey, v. 70, y, p. 19-34, 1997.

DESHPANDÉ, R.; FARLEY, J. U.; WEBSTER JR., F. E. Corporate culture, customer orientation and innovativeness in japanese firms: a quadrad analysis, Journal of Marketing, Chicago, v. 57, p. $23-27,1993$.

DULLEWICZ, V.; HIGGS, M. Assessing leadership styles and organizational context, Journal of Managerial Psychology, Bingley, v. 20, n. 2, p. 105-123, 2003.

ESTEVÃO, C. A. V. Redescobrir a escola privada portuguesa como organização na fronteira da sua complexidade organizacional, Braga: Universidade do Minho, 1998.

EUROPEN FOUDATION FOR QUALITY MANAGEMENT - EFQM. Os conceitos fundamentais da excelência, Bruxelas: EFQM, 2002.

FERREIRA, N. C.; TORRES, L. L. Perfil de liderança do diretor de escola em Portugal: modos de atuação e estratégias de regulação da cultura organizacional, Revista Brasileira de Política e Administração da Educação, Recife, v. 28, n. 1, p. 86-111, 2012.

FIOL, M. C.; HARRIS, D.; HOUSE, R. Charismatic leadership, Leadership Quartely, v. 10, n. 3, Atlanta: Elsevier Inc., p. 449-482, 1999.

FREITAS, A. I. F. P. A liderança do presidente da escola secundária Jaime Moniz no Funchal, 170 f. Dissertação (Mestrado em Administração e Gestão Educacional), Universidade Aberta, Lisboa, 2011.

FREITAS, H.; OLIVERA, M.; SACOOL, A. Z.; MOSCAROLA, J. O método de pesquisa survey, Revista de Administração, São Paulo, v. 35, n. 3, p. 105-112, jul./set. 2000.

FULLAN, M. Liderar numa cultura de mudança, Porto: Edições Asa, 2003.

GARZA, E.; DRYSDALE, L; GURR, D.; JACOBSON, S.; MERCHANT, B. Leadership for school success: lessons from effective principals, International Journal of Educational Management, Bingley, v. 28, n. 7, p. 798-811, 2014.

GÓIS, C. S. Lideranças transformacional, transacional e laissez-faire: um estudo de caso. 142 f. Dissertação (Mestrado em Supervisão Pedagógica e Formação de Formadores), Escola Superior de Educação Almeida Garrett, Lisboa, 2011.

GONÇALVES, L. C. C. Estilo de liderança e papel do coordenador do CAP na motivação da sua equipa. 184 f. Dissertação (Mestrado em Ciências da Educação), Universidade da Madeira, Funchal, 2011.

HARGREAVES, A.; FINK, D. Liderança sustentável, Porto: Porto Editora, 2009.

HERSEY, P.; BLANCHARD, K. Management of organizational behavior: Utilizing human resources. 5. ed. Englewwod Clifs, USA: Prentice-Hall. 1988. 
INOCÊNCIO, S. A. M. Estilo(s) de liderança dos diretores em escolas públicas não agrupadas do ensino secundário da região do Alentejo. 456 f. Tese (Doutorado em Educação), Universidade Aberta, Lisboa, 2013.

INOCÊNCIO, S. A. M.; RESENDES, L. C. G. Estilo(s) de liderança escolares, Fronteiras: Journal of Social, Technological and Environmental Science, Anápolis, v. 3, n. 3, jul./dez. p. 102-123. 2014.

JESUÍNO, J. C. Processos de liderança, Lisboa, Portugal: Livros Horizonte, 1987.

KIRKPATRICK, S. A.; LOCKE, E. A. Leadership: Do traits matter? Academy of Management Executive, v. 5, n. 2, New York, Academy of Management, p. 48-60, 1991.

LEITHWOOD, K. Leadership for school restructuring, Educational Administration Quartely, Thousand Oaks, v. 30, n. 4, p. 498-518, 1994.

LEITHWOOD, K.; DUKE, D. L. A century's quest to understand school leadership. In: MURPHY, J.; LOUIS, K. S. (ed.), Handbook of research on educational administration, San Francisco: Jossey-Bass, p. 45-72, 1999.

LEITHWOOD, K.; HARRIS, A.; HOPKINS, D. Seven strong claims about sucessful school leadership, School Leadership \& Management, London, v.28, n. 1, p. 27-42, 2008.

LEITHWOOD, K.; JANTZI, D. Transformational leadership: How principals can help reform school cultures, School Effectiveness and School Improvement, London, v. 1, n. 4, p. 249280, 1990.

LEITHWOOD, K.; JANTZI, D.; FERNANDEZ, A. Transformational leadership and teachers commitment to change. In: MURPHY, J.; LOUIS, K. S., Reshaping the principalship, Thousand Oaks, USA: Sage Publications, p. 77-89, 1994.

LEITHWOOD, K.; LOUIS, K. S.; ANDERSON, S.; WAHLSTROM, K. How leadership influences students learning. The Wallace Foudation. 2004. Disponível em: $<$ http://www. wallacefoundation.org/knowledge-center/school-leadership/key-research/Documents/How-Leadership-Influences-Student-Learning.pdf $>$. Acesso em: 15 jul. 2016.

LIKERT, R. Novos padrões de administração. 2. ed. São Paulo: Livraria Pioneira, 1979.

LIMA, J. A. Em busca da boa escola, Vila Nova de Gaia: Fundação Manuel Leão, 2008.

LÜCK, H. Liderança em gestão escolar, Petrópolis: Vozes Editora, 2008.

MARCONI, M. A.; LAKATOS, E. M. Fundamentos de metodologia científica. 5. ed. São Paulo: Editora Atlas, 2003.

MARZANO, R. Como organizar as escolas para o sucesso educativo: da investigação às práticas, Porto: ASA, 2005.

NYE, J. Liderança e poder. Lisboa: Editora Gradiva, 2009.

PACHECO, J. O pensamento e a acção do professor, Porto: Porto Editora, 1995.

PHIPPS, S. T.; PRIETO, L., C. The influence of personality factors on transformational leadership: exploring the moderating role of political skill, International Journal of Leadership Studies, Virginia Beach, v. 6, n. 3, p. 430-447, 2011. 
RICHARDSON, R. J. Pesquisa social: métodos e técnicas. 3. ed. São Paulo: Atlas, 2010. ROBBINS, S. P. Comportamento organizacional, 9 ed. São Paulo: Prentice Hall, 2002.

RODRIGUES, M. A. V. O tratamento e a análise de dados. In: SILVESTRE, H. C.; ARAÚJO, J. F. (coord.). Metodologia para investigação social, Lisboa: Escolar Editora, 2012.

SCHERMERHORN, J. R.; HUNT, J.; OSBORN, R. N. Fundamentos do comportamento organizacional. Porto alegre: Bookman, 1999.

SILVESTRE, H. C.; SILVESTRE, M. J. C. A área, o tema e o problema de pesquisa como factores determinantes no processo de investigação. In: SILVESTRE, H. C.; ARAÚJO, J. F. (coord.) Metodologia para investigação social, Lisboa: Escolar Editora, 2012.

STENTZ, J. E.; PLANO, C.; VICKI, L.; MATKIN, G. S. Applying mixed methods to leadership research: A review of current practice, The Leadership Quartely, Atlanta, v. 23, n. 4, p.1173-83, 2012.

TEJEDA, M. J.; SCANDURA, T. A.; PILLAI, R. The MLQ revisited psychometric properties and recomendations, The Leadership Quartely, Atlanta, v. 12, n. 1, p. 31-52, 2001.

TORRES, L. L. Cultura organizacional em contexto educativo - sedimentos culturais e processos de construção do simbólico numa escola secundária. 608 f. Tese (Doutorado em Educação), Universidade do Minho, Braga, 2003.

. A construção da autonomia num contexto de dependências: limitações e possibilidades nos processos de (in)decisão na escola pública, Revista Educação, Sociedade \& Culturas, Porto, n. 32, p. 91-109, 2011.

TORRES, L.L.; PALHARES, J. A. Estilos de liderança e escola democrática, Revista Lusófona de Educação, [S.I.], v. 14, n. 14, p. 77-99, 2009.

TRIGO, J. R.; COSTA, J. A. Liderança nas organizações educativas: a direcção por valores, Ensaio - Avaliação e Políticas Públicas em Educação, Rio de Janeiro, v. 16, n. 61, p. 561$582,2008$.

TUCKER, B. A.; RUSSEL, R. F. The influence of the transformational leader, Journal of Leadership and Organizational Studies, Thousand Oaks, v. 10, n. 4, p. 103-111, 2004.

TUCKMAN, B. Manual de investigação em educação, Lisboa: Fundação Calouste Gulbenkian, 2000.

WHITE, R.; LIPPITT, R. Comportamento do líder e reação dos membros em três climas sociais. In: CARTWRIGHT, D.; ZANDER, A. (org.). Dinâmica de grupo: pesquisa e teoria, v. 2, São Paulo: EPU USP, p. 590-597, 1975.

YANG, Y. Principals transformational leadership in school improvement, International Journal of Educational Management, Bingley, v. 28, n. 3, p. 279-288, 2014.

YIN, R. K. Estudo de caso: planejamento e métodos. 5. ed. Tradução Ana Thorell. Porto Alegre: Bookman, 2015.

YUKL, G. A. An evaluation of conceptual weaknesses in transformational and charismatic leadership theories, Leadership Quarterly, Atlanta, v. 10, n. 2, p. 285-305, 1999.

. Leadership in organizations. 7. ed. New Jersey: Pearson Education, 2010. 
Agradecimentos

Aos revisores e à editora de textos, que pelas sugestões e apontamentos enriqueceram sobremaneira este trabalho.

Recebido em: 16-08-2016

Aprovado em: 24-04-2017

Avaliado pelo sistema double blind review.

Editor: Elmo Tambosi Filho

Disponível em http://mjs.metodista.br/index.php/roc 